\title{
Vertical distributions of the microscopic morphological characteristics and elemental composition of aerosols over India
}

\section{Gogoi, Mukunda M.}

2020-12

Gogoi , M M , Thakur , R C , Gazi , S , Nair , V S , Mohan , R \& Babu , S S 2020 , ' Vertical distributions of the microscopic morphological characteristics and elemental composition of aerosols over India ' , Journal of Atmospheric Chemistry , vol. 77 , no. 4 , pp. 117-140 . https://doi.org/10.1007/s1087

http://hdl.handle.net/10138/324340

https://doi.org/10.1007/s10874-020-09406-5

cc_by

publishedVersion

Downloaded from Helda, University of Helsinki institutional repository.

This is an electronic reprint of the original article.

This reprint may differ from the original in pagination and typographic detail.

Please cite the original version. 


\title{
Vertical distributions of the microscopic morphological characteristics and elemental composition of aerosols over India
}

\section{Mukunda M. Gogoi, et al. [full author details at the end of the article]}

Received: 25 March 2020 / Accepted: 5 July 2020 /

Published online: 14 August 2020

(C) Springer Nature B.V. 2020

\begin{abstract}
Particle morphology and elemental compositions are among the crucial parameters of aerosols required for accurate understanding of the climatic effect of aerosols in the earth-atmosphere system; yet their vertical distributions and region specific properties are poorly characterised due to sparse in-situ measurements. This is the first study to classify and quantify the vertical distributions of the morphological characteristics and elemental composition of aerosols based on single particle as well as bulk chemical analysis over seven geographically diverse regions of northern and central parts of India during spring (April-May, 2013), carried out as a part of Regional Aerosol Warming Experiment (RAWEX). Significant regional distinctiveness in shapes (non-sphericity), sizes and elemental compositions of the airborne particles were conspicuous, having dominance of highly irregular granular aggregates over the north Indian sites. The non-spherical coarse mode particles dominated the lower free tropospheric regions $(>2 \mathrm{~km}$ ) of the Indo-Gangetic Plains (IGP). These particles could be responsible for enhanced spring time aerosol absorption in the elevated region of the atmosphere. Elemental compositions of the single particle analysis indicate that the free tropospheric layer over the IGP and central India is enriched with $\mathrm{Na}$ and $\mathrm{Ca}$ compounds mixed with $\mathrm{Fe}$ or $\mathrm{Al}$ (soil particles), indicating long range transport of crustal aerosols. This finding is very well supported by the bulk particle analysis indicating abundance of $\mathrm{Ca}^{2+}$ in the free troposphere with low contribution of $\mathrm{ssNa}^{+}$. Particles with irregular rough surfaces having dominance of $\mathrm{SiO}_{2}$ were observed over all the study sites. The percentage share of spherical (either smooth or rough) particles to the total morphological characteristics of the particles was found to be highly subdued $(<10 \%)$. The present study thus critically assesses the relevant knowledge pertaining to the morphological features of aerosols over the IGP during spring for the accurate estimation of aerosol radiative properties. More such efforts are required in future to study the connections and dependencies between morphological and radiative properties of aerosols in different seasons.
\end{abstract}

Keywords Aerosol · Particle morphology · Elemental composition · IGP

\section{Introduction}

Accurate characterization of the complex spatio-temporal variability of aerosols over southAsia still remains a challenge due to complexity of the highly heterogenous emission sources 
and the associated transformation and transport processes, rendering susceptibility in the understanding and prediction of aerosol-radiation and aerosol-cloud interactions. For deeper insight in to the origin and transformation of particles, knowledge about the particle morphology and elemental compositions are important. However, their region specific properties and vertical distributions are poorly characterised due to sparse in-situ measurements. In recent years, a few campaign mode airborne measurements have demonstrated the altitude-resolved physical and optical properties of aerosols and their potential influence on radiative interactions and cloud-condensation nuclei activation over geographically diversified locations of India (e.g., Babu et al. 2016; Nair et al. 2016; Padmakumari et al. 2017; Vaishya et al. 2018; Brooks et al. 2019; Gogoi et al. 2019; Jayachandran et al. 2020). These studies have revealed significant contribution of coarse mode (polluted) dust and Black Carbon (BC) to elevated aerosol load across the IGP in spring, playing a crucial role in governing the radiation balance through diabatic heating of the upper atmosphere. Under such circumstances, the study of the vertical distributions of aerosol physical structure and chemical composition is very useful for understanding the particle morphology and turbulence interaction under the influence of thermal convective and horizontal transport processes. Since, the particles are constantly restructured through coagulation, condensation and other aging processes, the relevant knowledge pertaining to the morphological features and elemental compositions of individual particles is essential for the accurate estimation of aerosol radiative properties.

In this regard, scanning electron microscopy (SEM) with energy-dispersed X-ray Spectroscopy (EDS) and transmission electron microscopy (TEM) analysis helps in the accurate assessment of primary and secondary source mechanisms of aerosols, their reactivity, transport and removal processes in the atmosphere (Choěl et al. 2005; Laskin et al. 2006). Over the past decade, the EDS and TEM analysis (both studying elemental composition) coupled with SEM (studying morphological structures characteristics) has formed an important tool to characterize the physico-chemical properties of single aerosol particles (Tsuji et al. 2008). Over the Indian region, SEM-EDS analysis have been extensively used (Sachdeva and Attri 2008; Srivastava et al. 2009; Agrawal et al. 2011; Pipal et al. 2011; Pachauri et al. 2013; Singh et al. 2014; Gupta et al. 2019) for the bulk-particle analysis to characterize unique features of aerosols delineating the highly heterogeneous seasonally varying source processes over distinct geographic environments. All of these studies highlight the unique features of aerosols emanating from the biogenic, geogenic or anthropogenic sources. However, most of the aerosol samples involved in these studies were collected from regions near to the earth surface, hence the information of particle morphology in a 3-D space was not identified so far.

In this study, we classify and quantify, for the first time, the vertical distributions (within and above the boundary layer) of microscopic morphological characteristics and elemental and ionic compositions of aerosols over seven geographically diverse locations of northern and central India, based on the aerosol samples collected onboard a research aircraft during spring (April-May, 2013) as a part of Regional Aerosol Warming Experiment (RAWEX), a project under the Indian Space Research Organization's Geosphere Biosphere Program (ISRO-GBP).

\section{Methodology}

The aerosol samples for SEM-EDS analysis were collected from two distinct regions of the atmosphere [within and above the well mixed boundary layer confined between $0.5-4 \mathrm{~km}$ above ground level (AGL)]. The lower atmospheric region, 0.5-2 km AGL, will be termed as 
bottom layer (BL, henceforth) and the lower free tropospheric region, 2.0-4.0 km AGL, will be termed as top layer (TL, henceforth). Circular quartz-fibre filters (Whatman ${ }^{\mathrm{TM}}$; $96 \mathrm{~mm}$ diameter) were used in an indigeniously built aerosol sampler for in-situ collection of aerosol samples by aspiring air through a isokinetic inlet fitted (front-facing) at the bottom of the fugelage. To maintain the isokinetic flow, the aircraft speed was maintained at $300 \mathrm{~km} / \mathrm{h}$. The in-situ sampling of aerosols were carried out during 24th April to 25th May, 2013 over (i) Hyderabad (HYD), (ii) Nagpur (NGP), (iii) Lucknow (LKN), (iv) Patna (PTN), (v) Dehradun (DDN), (vi) Jodhpur (JDR) and (vii) Jaipur (JPR), representing distinct aerosol environments of central and northern parts of India. The geographical positions of these sites are shown in Fig. 1. Over each of these selected sites, the pattern of flight sorties were uniformly maintained, making sorites at six altitude levels within $0.5-4 \mathrm{~km}$ range with about thirty minutes of operation at each level. This sampling stretagy was made based on the aircraft endurance $(4 \mathrm{~h})$ and the ceiling altitude permissible for unpressurized mode of operation $(\sim 4 \mathrm{~km})$. The details about the aircraft experiment is included in our recent papers (Babu et al. 2016; Nair et al. 2016; Gogoi et al. 2019).

The selected locations in the present study are identified as the hotspots of urban/ anthropogenic/ arid sources of aerosols, which experience distinct radiative perturbations due to region-specific physical, chemical and optical properties of aerosols. Located in the middle of the Indo-Gangetic Plains, the city of Lucknow (LKN, $26.76^{\circ} \mathrm{N}, 80.88^{\circ} \mathrm{E}, 123 \mathrm{~m}$ a.s.1.) posesses high particulate matter concentration (WHO Global Ambient Air Quality Database). Similarly, Patna (PTN, $25.59^{\circ} \mathrm{N}, 85.09^{\circ} \mathrm{E}, 54.5 \mathrm{~m}$ a.s.1.) in the eastern part of the IGP is also prone to higher aerosol concentrations. Jodhpur (JDR; $26.25^{\circ} \mathrm{N}, 73.05^{\circ} \mathrm{E}, 426 \mathrm{~m}$ a.s.1.) and Jaipur (JPR; $26.83^{\circ} \mathrm{N}, 75.82^{\circ} \mathrm{E}, 431 \mathrm{~m}$ a.s.1.) are the arid locations in the western part of India. Dehradun (DDN; $30.19^{\circ} \mathrm{N}, 78.18^{\circ} \mathrm{E}, 670 \mathrm{~m}$ a.s.l.) is located in a valley in the Shiwalik range, the foothill region of Himalayas. Nagpur (NGP; $21.15^{\circ} \mathrm{N} ; 79.15^{\circ} \mathrm{E}, 300 \mathrm{~m}$ a.s.l.) and Hyderabd (HYD; $17.39^{\circ} \mathrm{N} ; 78.49^{\circ} \mathrm{E}, 557 \mathrm{~m}$ a.s.1.) are located in the central and peninsular regions of India respectively.

A total of 14 samples (2 samples from individual locations; one from the bottom and other from the top layer of the atmosphere) were collected period with sampling duration of $1.5-2 \mathrm{~h}$ for each of the samples. From these samples, a total of 1671 particles were scanned in SEM to understand the vertical heterogeneity in thel morphology and elemental compositions of
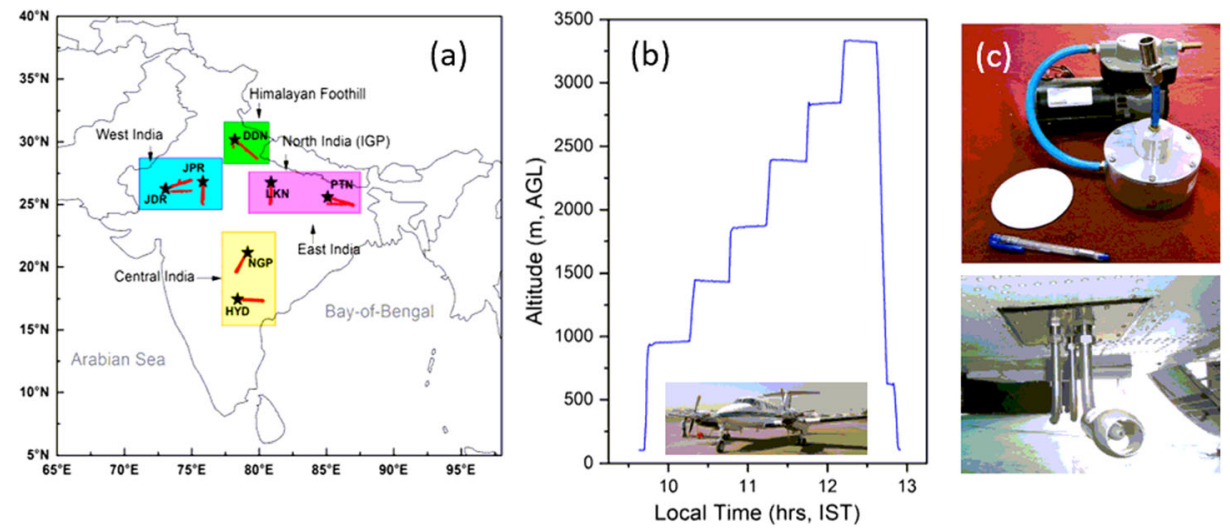

Fig. 1: (a) Geographical sites of aircraft experiment, (b) Typical staircase pattern of flight operations for aerosol sampling at different altitude zones of the atmosphere, and (c) the aerosol sampler and inlet system used in the study 
aerosols over seven geographically diverse locations of India. SEM-EDS analysis of the aerosol samples were carried out at National Centre for Polar and Ocean Research (NCPOR), Goa by using computer controlled SEM (Make: JEOL, Model: JSM 6360 LV) equipped with an EDS (Model: OXFORD INCA 150). Further, chemical analysis of the aerosols was also carried out with ion chromatography technique. The details of samplings and the corresponding altitude information are given in Table 1.

In the present study, aerosol samples were collected using quartz filters as the sample collection time was less than 2-h at each of the two distinct altitude regions of the atmosphere during individual flight sorties. Quartz, along with Teflon and Mixed Celluloose Ester (MCE) are known as "depth" filters, which trap particles throughout the depth of the filter rather than on the surface. Thus, Quartz filters are suitable for efficient sample collection during short sampling period. There are several studies (e.g., Pachauri et al. 2013; Suárez-Peña et al. 2016) which show the effectiveness of SEM-EDX analysis based on aerosol samplings in Quartz filters. However, as the quartz filters are fibrous in nature, many fine particles may hide in the filter and SEM may not be able to detect all the particles in the filter. To overcome this uncertainty, around 100 field of views is scanned per filter sample for calculation of each shape.

Since quartz filters are made up of "SiO 2 " and traces of other elements like $\mathrm{Na}$, $\mathrm{Al}$, we have obtained the EDX spectra of blank quartz fiber filter to minimize the error in the estimation of elemental concentrations in the particles. Subsequently, the composition of blank quartz filter was subtracted from the EDX spectra of individual aerosol particles. Within these uncertainties, Quartz filters are one among the four most commonly used filter types; which includes Teflon, Mixed Celluloose Ester (MCE) and Polycarbonate membrane. The polycarbonate screen membranes, also called Nuclepore, are suggested to collect samples for SEM-EDS analysis effectively as these are mechanically rugged and are an excellent substrate for automated particle analysis (Willis et al. 2002).

It is to be noted that, the quartz fiber filters used for samplings were pre-heated (at $800{ }^{\circ} \mathrm{C}$ ) for $3 \mathrm{~h}$ in a muffle furnace to remove the organic impurities. Similarly, the sampled filters were wrapped in aluminum foil and sealed in polyethylene ziplock bags immediately after each of the sampling at different heights and locations and stored in freezer until the time of analysis to prevent the evaporation of volatile components.

Table 1. Operation details of aircraft at different locations of India during spring-2013.

\begin{tabular}{|c|c|c|c|c|c|}
\hline Region & Location & $\begin{array}{l}\text { Sortie details (Apr-May) } \\
2013\end{array}$ & $\begin{array}{l}\text { Sampling } \\
\text { details }\end{array}$ & $\begin{array}{l}\text { Bottom } \\
\text { Layer }\end{array}$ & Top Layer \\
\hline \multirow[t]{2}{*}{ Central India (CI) } & $\begin{array}{l}\text { Hyderabad } \\
\text { (HYD) }\end{array}$ & 25/26/27 Apr & $27 / 4 / 2013$ & $0.5-1.5 \mathrm{~km}$ & $2.0-3.0 \mathrm{~km}$ \\
\hline & Nagpur (NGP) & 30 Apr, 1/ 2 May & $\begin{array}{l}30 / 4 / 2013 \\
02 / 5 / 2013\end{array}$ & $1.0-2.0 \mathrm{~km}$ & $\begin{array}{l}2.3-3.3 \mathrm{~km} \\
--\end{array}$ \\
\hline \multirow[t]{2}{*}{$\begin{array}{l}\text { Indo Gangetic Plains } \\
\text { (IGP) }\end{array}$} & $\begin{array}{l}\text { Lucknow } \\
(\mathrm{LKN})\end{array}$ & 5/ 6/ 7 May & $05 / 5 / 2013$ & $0.9-1.8 \mathrm{~km}$ & $2.2-3.2 \mathrm{~km}$ \\
\hline & Patna (PTN) & 9/10/12 May & $12 / 5 / 2013$ & $0.9-1.9 \mathrm{~km}$ & $2.3-3.2 \mathrm{~km}$ \\
\hline $\begin{array}{l}\text { Himalayan Foothill } \\
\text { (HF) }\end{array}$ & $\begin{array}{l}\text { Dehradun } \\
\text { (DDN) }\end{array}$ & 14/ 15/ 16 May & $\begin{array}{l}14 / 5 / 2013 \\
15 / 5 / 2013\end{array}$ & $\begin{array}{l}-- \\
--\end{array}$ & $\begin{array}{l}2.8-3.8 \mathrm{~km} \\
2.8-3.8 \mathrm{~km}\end{array}$ \\
\hline \multirow[t]{2}{*}{$\begin{array}{l}\text { Western India } \\
\text { (WI) }\end{array}$} & Jodhpur (JDR) & 18/ 20 May & $\begin{array}{l}18 / 5 / 2013 \\
20 / 5 / 2013\end{array}$ & $\begin{array}{l}0.5-1.7 \mathrm{~km} \\
--\end{array}$ & -- \\
\hline & Jaipur (JPR) & 22/ 23/ 24 May & $\begin{array}{l}22 / 5 / 2013 \\
23 / 5 / 2013\end{array}$ & $\begin{array}{l}-- \\
0.9-1.7 \mathrm{~km}\end{array}$ & $\begin{array}{l}0.5-1.7 \mathrm{~km} \\
--\end{array}$ \\
\hline
\end{tabular}




\subsection{SEM-EDS analysis}

For the SEM-EDS analysis of the samples, the central parts of the filter were cut into a square $\left(1 \times 1 \mathrm{~mm}^{2}\right)$ assuming that this part is the most heavily loaded with the particulate matter. Following this, each of the samples were placed on a conductive carbon tape placed on an aluminium SEM holder. The samples were then placed in a high vacuum SEM chamber for morphological analysis. As also, from each geographical location, $1 \mathrm{~mm}^{2}$ filter paper is scanned at 2000X-3000X magnification for counting the number of aerosol particles of each shape. On an average, 100 particles were scanned per filter at 2000X-3000X magnification.

By carefully selecting the most probable heavy metals and secondary inorganic compounds ( $\mathrm{Na}, \mathrm{Mg}, \mathrm{Ca}, \mathrm{Mn}, \mathrm{Cl}, \mathrm{S}, \mathrm{N}, \mathrm{Fe}, \mathrm{Pb}, \mathrm{Al}, \mathrm{Si}, \mathrm{Cr}$ ), a micro-analysis was performed by EDS coupled with the SEM. The EDS analysis was carried out using $60 \mathrm{~s}$ of capture time and most of the time the central part of the single particle was taken into consideration while recording the spectra from EDS. Both the weight and atomic percentage of the spectra were recorded. This SEM-EDS analysis was performed for each of the samples collected at two distinct vertical zones of different geographical locations in India.

\subsection{Chemical analysis}

The filter samples were further used for the chemical analysis using appropriate techniques to determine various ionic species with minimum uncertainty. To carry out the analysis, samples from the filter punches were extracted using ultra-sonication for $30 \mathrm{~min}$ in $20 \mathrm{ml}$ Milli-Q water and filtered by a syringe filter of $0.22 \mu \mathrm{m}$ pore size. The extracts were subsequently analyzed for major ions by a reagent-free ion chromatography (RF-IC) system (DX-2500 and ICS-2000, Dionex, USA) placed in a class 100 clean room and equipped with an automated Eluent Generator Module (EG50, Dionex, USA) and conductivity detector (CD25, Dionex, USA). The cations were separated on an IonPac CS17 (4 mm) column with methane sulfonic acid (MSA) as eluent at a flow rate of $1.0 \mathrm{~mL} / \mathrm{min}$, using the gradient method and an IonPac CG17 Guard column with a CSRS-ULTRA suppressor. The anions were separated on an IonPac AS11-HC (4 mm) column with potassium hydroxide $(\mathrm{KOH})$ at $1.2 \mathrm{~mL} / \mathrm{min}$ as eluent, using gradient method and an IonPac AG11-HC Guard column, with an ASRS-ULTRA (4 mm) suppressor. Calibration was done using concentration range of 50-500 ppb IV (Inorganic Ventures, USA) high-purity standards. In order to confirm the quality of measurements, chromatographic standards were analyzed on a daily basis throughout the study. The precision estimated from the standard deviation of repeat measurements of standard and samples was $3 \%$ for $\mathrm{Na}^{+}, \mathrm{K}^{+}, \mathrm{Mg}^{2+}$ and $\mathrm{Ca}^{2+} ; 4 \%$ for $\mathrm{NH}_{4}+; 6 \%$ for $\mathrm{Cl}^{-}$and $4 \%$ for $\mathrm{NO}_{3}{ }^{-}$and $\mathrm{SO}_{4}{ }^{2-}$. The total mass of inorganic water-soluble ions $\left(\mathrm{Na}^{+}, \mathrm{NH}_{4}^{+}, \mathrm{K}^{+}, \mathrm{Ca}^{2+}, \mathrm{Mg}^{2+}, \mathrm{Cl}^{-}, \mathrm{NO}_{3}{ }^{-}\right.$and $\left.\mathrm{SO}_{4}{ }^{2-}\right)$ were estimated and the $\%$ contribution of each of the ions to the total mass was also calculated.

Apart from the analytical errors, the experimental uncertainty of the filter sampling was checked by field blanks determination of the particulate samples. The field blanks were collected for each of the days of flight operations by mounting the Whatman filter paper in the sampler and operating the sampler for one minute, as detailed in Kumar and Kumari (2015) and Kumar et al. (2007). The average concentration the analytes was found to be below the detection limits, ensuring minimal sources of contamination of the filters in the ambient condition. 


\section{Presentation of results}

We classify the SEM images of various shapes into different categories for understanding their spatio-temporal heterogeneities and delineating source processes at different altitude over distinct geographic regions of India. Further, the elemental composition corresponding to each of the morphological shapes are also investigated based on EDS analysis of the respective samples.

\subsection{Identification of major particle types}

The major aerosol types prevailing over the Indian region during the period of spring (2013) are found to possess many physical structures, which are segregated into eight distinct categories, viz., (i) spherical smooth (SS), (ii) spherical rough (SR), (iii) rectangular smooth (RS), (iv) rectangular rough (RR), (v) triangular smooth (TS), (vi) triangular rough (TR), (vii) irregular rough (IR) and (viii) irregular aggregated/ granular/ chain like (MISC) particles. Based on this classification, the elemental compositions of each of the particles bearing distinct shapes and sizes are examined.

The typical SEM images of each of the distinct particulate types are shown in Fig. 2. The quantifying parameters of different shapes are also shown in the figure, alsoand the numerical values are listed in Table 2. Computer controlled SEM with its in-built operational software was used to determine the particle size and shape parameters (length, perimeter, diameter etc). Based on the SEM-EDS analysis, the particles (regular/ irregular form) are classified and sorted based on size, shape and chemistry. The results demonstrate that the dimensions of the particles in the present study varied over a wide range from $2.63 \mu \mathrm{m}$ diameter of spherical particles to $37.6 \mu \mathrm{m}$ long rectangular smooth particles. Similarly, the length of irregular aggregated particles is also found to be $18.8 \mu \mathrm{m}$, the perimeter of which is comparable to that of granular chain like particles. On the other hand, dimensions of spherical smooth, irregular smooth, spherical rough and irregular rough particles are nearly comparable.

Since the relative dominance of these shapes of particles is dependent on the compositional variability, which is region specific, elemental compositions of each of the distinct particulate types are discussed below before quantifying their altitudinal change and regional distinctiveness over different parts of India.

\subsubsection{Irregular rough particles}

Figure 3 shows the typical irregular rough particles and the corresponding energy dispersion spectrum in the bottom panel. Physically, these type of particles are found to have largest dimensions (length $\sim 10 \mu \mathrm{m}$ ). The weight and atomic percentages of these particles reveals the dominanace of $\mathrm{Si}$ and $\mathrm{O}_{2}$ in their composition as compared to other elements (Table 3), where the weight $\%$ of Si varies between $26 \%$ and $36 \%$, while that of $\mathrm{O}$ between $59 \%$ and $70 \%$, thus adhering to the most probable form of $\mathrm{SiO}_{2}$. These types of particles originate mainly from the sand used in construction activities in an urban area or those transported from the arid (sandy) locations. 
(a)

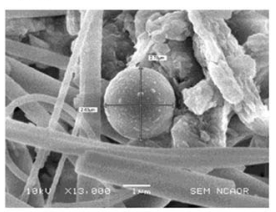

(c)

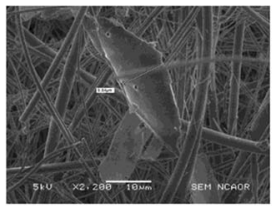

(e)

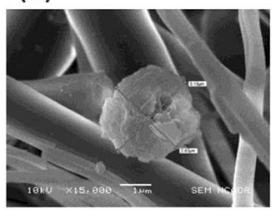

(g)

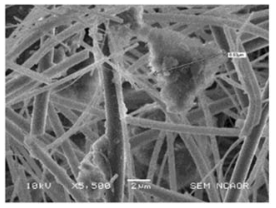

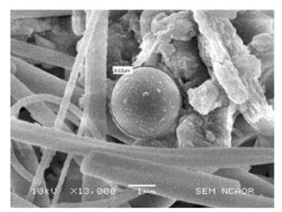

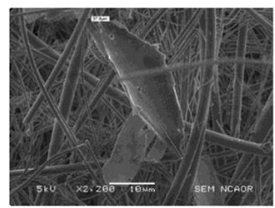

(f)
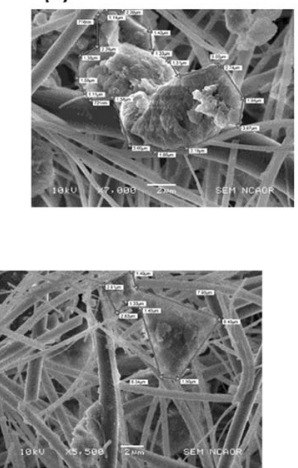

(b)
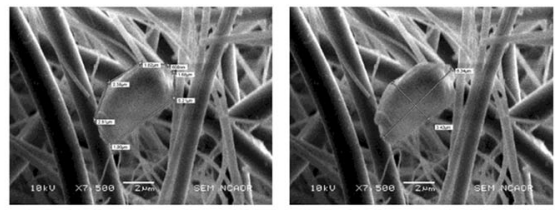

(d)
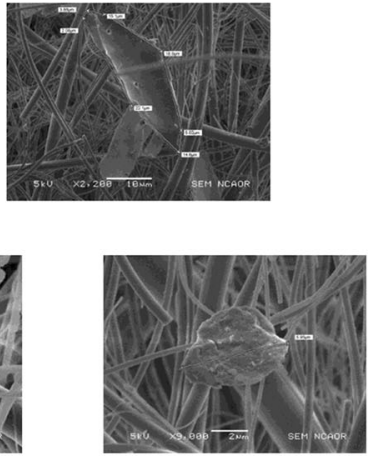

(h)

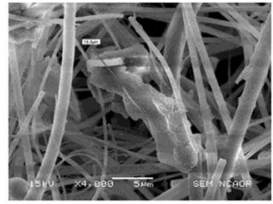

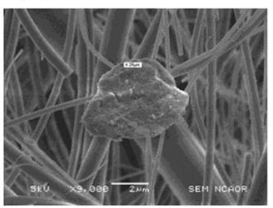
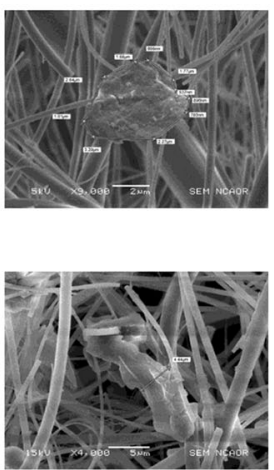

Fig. 2: Typical morphological structures of aerosol particles seen over the Indian region during spring-2013; which include (a) spherical smooth, (b) irregular smooth, (c) rectangular smooth, (d) irregular rough, (e) spherical rough, (f) granular chain like, (g) triangular rough, and (h) irregular aggregated. The shape parameters, such as length, thickness and perimeter of the particles are also shown

\subsubsection{Triangular/ rectangular/ spherical roughparticles: rich in $\mathrm{Cr}, \mathrm{Mn}, \mathrm{Ca}$ and $\mathrm{Fe}$}

Figure 4 shows triangular, rectangular and spherical rough particles, having dimenstion smaller $(<10 \mu \mathrm{m})$ than the irregular rough particles. These particles how visible surface enrichments of metals. The corresponding weight $\%$ and atomic $\%$ of these particles in Table 4 clearly indicate that these particles are rich in $\mathrm{Cr}$, in addition to $\mathrm{Si}$ and $\mathrm{O}$. Industrial (metalliferous particles) or vehicular (dust) activities are the prime sources of such particles, enriched with $\mathrm{Cr}$.

Table 2. The shape parameters of different particles shown in Fig. 2

\begin{tabular}{lllll}
\hline Figure & Shape & Thickness $(\mu \mathrm{m})$ & Length $(\mu \mathrm{m})$ & Perimeter $(\mu \mathrm{m})$ \\
\hline $2(\mathrm{a})$ & Spherical smooth & 2.63 & 2.75 & 8.63 \\
$2(\mathrm{~b})$ & irregular smooth & 3.43 & 6.34 & 16.2 \\
$2(\mathrm{c})$ & rectangular smooth & 9.84 & 37.6 & 80.76 \\
$2(\mathrm{~d})$ & irregular rough & 4.26 & 5.95 & 15.78 \\
$2(\mathrm{e})$ & spherical rough & 2.82 & 3.19 & - \\
$2(\mathrm{f})$ & granular chain like & - & - & 36.25 \\
$2(\mathrm{~g})$ & triangular rough & 6.53 & - & 32.15 \\
$2(\mathrm{~h})$ & irregular aggregated & 4.44 & 18.8 & 47.81 \\
\hline
\end{tabular}


Industrial activities include metal processing, coal burning and fossil fuel combustions (Kotas and Stasicka 2000). The diesel emissions from vehicular traffic in the cities have abundant $\mathrm{Cr}$ in the emitted particles (Wang et al. 2003). In addition, the rectangular particles are Fe-rich (along with Cr-Mn-O) indicating various other sources of aerosols, such as the wear and tear of tyres, oil burning, abrasion of mechanical parts of road vehicles, oil lubricants etc. (Pachauri et al. 2013; Adachi and Tainosho 2004). The Cr particles also have Mn enrichment, which could be sourced from the unleaded gasoline used in automobiles.

\subsubsection{Spherical smooth particles: rich in $\mathrm{N}$}

Figure 5 shows the typical spherical smooth particles, indicating their likely noncrystalline, amorphous state. EDS analysis shows the signals of $\mathrm{N}$ and $\mathrm{O}$ in these types of particles, indicating the presence of nitrates. $\mathrm{HNO}_{3}$ is originated from anthropogenic activities (fossil fuel combustions) in the troposphere. Further, the presence of Ammonia (NH ) in urban cities cannot be ignored. $\mathrm{NH}_{3}$ can be released from animal waste, fertilizer application, soil release, and industrial emissions. However, the formation of ammonium nitrate depends a lot on environmental factors (temperature, humidity) and the availability of sulphuric acid $\left(\mathrm{H}_{2} \mathrm{SO}_{4}\right)$ and $\mathrm{HNO}_{3}$. However these spherical smooth particles are also found to be coagulated with metal (Fe, Sample-1) or mixed with fine grained mineral particles (Al, Sample -2). These particles were mostly below $2.5 \mu \mathrm{m}$, so could be long range transported to the study sites (Table 5). All these findings suggest that the probability of the presence of nitrates as $\mathrm{NaNO}$ and $\mathrm{Ca}\left(\mathrm{NO}_{3}\right)_{2}$ is more as compared to $\mathrm{NH}_{4} \mathrm{NO}_{3}$. Further quantification of different ions in the aerosols were carried out through ion chromatography and results are discussed in detail in a subsequent section, which provides a more comprehensive view.

\subsubsection{Highly irregular particles: rich in metal aggregates.}

Aggregates of metalliferous aerosol particles having highly irregular shapes are also seen during our experiment. These are shown in Fig. 6, along with the information of weight\% and atomic\% in Table 6. Metalliferous particles are mainly rich in $\mathrm{Fe}$ and aggregates of $\mathrm{Fe}, \mathrm{Si}$ and
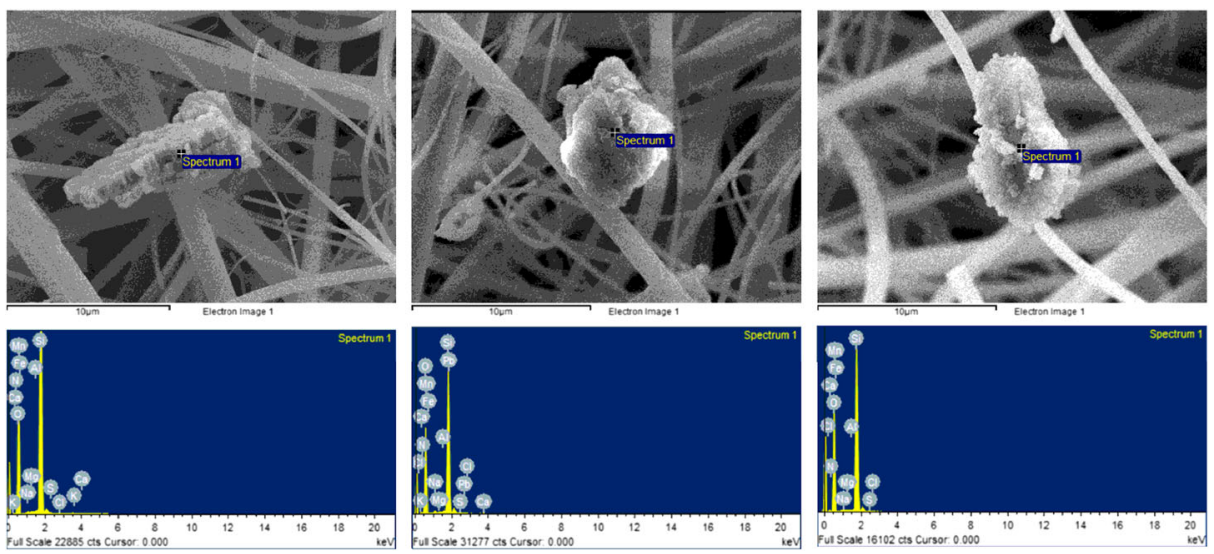

Fig. 3: Typical irregular shape particles; followed by their corresponding energy dispersion spectrum in the bottom panel. X-axis is indicative of X-ray energy while the Y-axis is indicative of X-ray count for each individual element 
Table 3. Weight $\%$ and Atomic $\%$ of the elements corresponding to the irregular rough particles shown in Fig. 3

\begin{tabular}{|c|c|c|c|c|c|c|}
\hline \multirow[t]{2}{*}{ Element } & \multicolumn{2}{|c|}{$\begin{array}{l}\text { Sample-1 (irregular rough } \\
\text { particle) }\end{array}$} & \multicolumn{2}{|c|}{$\begin{array}{l}\text { Sample-2 (irregular rough } \\
\text { particle) }\end{array}$} & \multicolumn{2}{|c|}{$\begin{array}{l}\text { Sample-3 (irregular rough } \\
\text { particle) }\end{array}$} \\
\hline & Weight $\%$ & Atomic $\%$ & Weight $\%$ & Atomic\% & Weight $\%$ & Atomic\% \\
\hline $\mathrm{N}$ & 3.36 & 4.55 & 4.36 & 5.67 & 2.77 & 3.56 \\
\hline $\mathbf{O}$ & 59.17 & 70.15 & 66.10 & 75.28 & 70.04 & 78.98 \\
\hline $\mathrm{Na}$ & 0.24 & 0.20 & 0.52 & 0.41 & 0.14 & 0.11 \\
\hline $\mathrm{Mg}$ & 0.08 & 0.06 & 0.10 & 0.07 & 0.03 & 0.02 \\
\hline $\mathrm{Al}$ & 0.02 & 0.01 & 0.24 & 0.16 & 0.03 & 0.02 \\
\hline $\mathbf{S i}$ & 36.92 & 24.93 & 27.89 & 18.09 & 26.80 & 17.21 \\
\hline S & 0.04 & 0.03 & 0.08 & 0.05 & 0.06 & 0.04 \\
\hline $\mathrm{Cl}$ & 0.03 & 0.01 & 0.05 & 0.02 & 0.01 & 0.01 \\
\hline K & 0.00 & 0.00 & 0.04 & 0.02 & 0.07 & 0.03 \\
\hline $\mathrm{Ca}$ & 0.06 & 0.03 & 0.17 & 0.08 & 0.02 & 0.01 \\
\hline $\mathrm{Mn}$ & 0.08 & 0.03 & 0.08 & 0.03 & 0.02 & 0.00 \\
\hline
\end{tabular}

other elements; On the other hand, metalliferous particles rich in $\mathrm{Cr}$ form aggregates with $\mathrm{Mn}$ along with Si. Such particles usually originate from resuspension of road dust due to vehicular activities, metallic abrasions, oil combustion and lubricants (Pachauri et al., 2013). Unleaded gasoline contains $\mathrm{Mn}$ as an additive. Therefore such particles are commonly found in densely populated urban areas.

\subsection{Classification of particulate morphology at distinct altitude zones}

With a view to examine the relative dominance of various particulate morphologies at distinct altitude zones of different geographical sites of India, the particles of similar shapes are grouped together and their percentage occurrences are calculated. This is shown in Fig. 7, separately for two distinct altitude zones over all the observational sites.

Irregular rough (IR) particles are found to dominate over most of the sites irrespective of the sampling altitudes, except those in the bottom layers $(\mathrm{BL},<2 \mathrm{~km})$ of NGP and PTN. Spherical

(a)
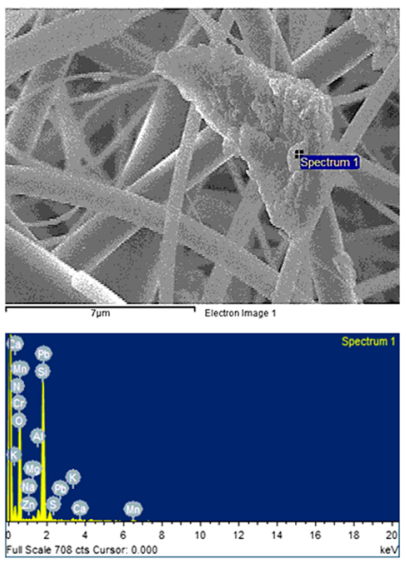

(b)
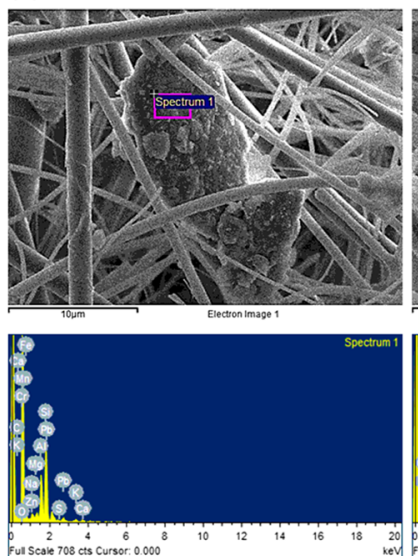

(c)
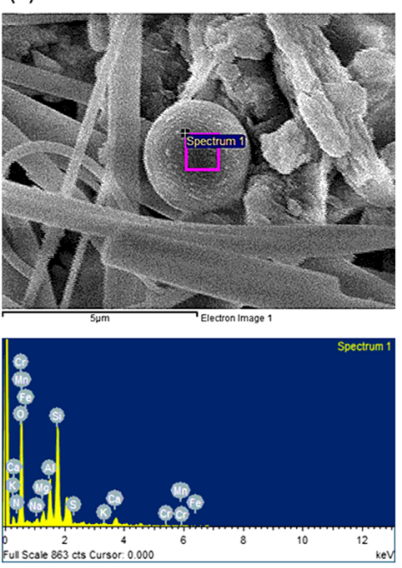

Fig. 4: (a) Triangular rough particle of $\mathrm{Cr}$ and $\mathrm{Mn}(>5 \mu \mathrm{m})$; (b) Rectangular rough particles enriched in $\mathrm{Cr}, \mathrm{Mn}$ and $\mathrm{Fe}(>5 \mu \mathrm{m})$; (c) Spherical rough particles highly mixed with $\mathrm{Cr}, \mathrm{Mn}, \mathrm{Ca}$ and $\mathrm{Fe}(<3 \mu \mathrm{m})$ 
Table 4. Weight $\%$ and Atomic\% of the elements corresponding to the mineral aerosol particles shown in Fig. 4

\begin{tabular}{|c|c|c|c|c|c|c|c|c|}
\hline \multicolumn{3}{|c|}{ Sample-1 (triangular rough particle) } & \multicolumn{3}{|c|}{ Sample-2 (rectangular rough particle) } & \multicolumn{3}{|c|}{ Sample-3 (spherical rough particle) } \\
\hline Element & Weight $\%$ & Atomic $\%$ & Element & Weight $\%$ & Atomic\% & Element & Weight $\%$ & Atomic $\%$ \\
\hline $\mathbf{N}$ & 9.33 & 13.24 & $\mathbf{O}$ & 30.88 & 49.81 & $\mathbf{N}$ & 6.15 & 10.04 \\
\hline $\mathbf{O}$ & 50.51 & 62.75 & $\mathrm{Na}$ & 0.46 & 0.51 & $\mathbf{O}$ & 40.14 & 57.33 \\
\hline $\mathrm{Na}$ & 0.23 & 0.20 & $\mathrm{Mg}$ & 0.50 & 0.53 & $\mathrm{Na}$ & 0.73 & 0.73 \\
\hline $\mathrm{Mg}$ & 0.38 & 0.31 & Al & 3.06 & 2.93 & $\mathrm{Mg}$ & 1.26 & 1.18 \\
\hline $\mathrm{Al}$ & 1.24 & 0.92 & $\mathbf{S i}$ & 6.39 & 5.88 & Al & 5.27 & 4.47 \\
\hline $\mathbf{S i}$ & 24.57 & 17.39 & $\mathrm{~S}$ & 0.00 & 0.00 & Si & 14.49 & 11.79 \\
\hline $\mathrm{S}$ & 0.28 & 0.17 & $\mathrm{~K}$ & 0.36 & 0.23 & $\mathrm{~S}$ & 0.20 & 0.15 \\
\hline $\mathrm{K}$ & 0.85 & 0.43 & $\mathrm{Ca}$ & 0.39 & 0.25 & $\mathrm{~K}$ & 0.45 & 0.26 \\
\hline $\mathrm{Ca}$ & 0.55 & 0.27 & $\mathrm{Cr}$ & 25.77 & 12.79 & $\mathrm{Ca}$ & 3.25 & 1.85 \\
\hline $\mathrm{Cr}$ & 10.62 & 4.06 & Mn & 13.06 & 6.14 & $\mathrm{Cr}$ & 23.13 & 10.17 \\
\hline Mn & 0.36 & 0.13 & $\mathrm{Fe}$ & 10.79 & 4.98 & Mn & 2.69 & 1.12 \\
\hline $\mathrm{Zn}$ & 0.09 & 0.03 & $\mathrm{Zn}$ & 0.22 & 0.09 & $\mathrm{Fe}$ & 2.22 & 0.91 \\
\hline $\mathrm{Pb}$ & 0.96 & 0.09 & & & & & & \\
\hline
\end{tabular}

smooth (SS) particles were most abundant in the central India and in the lower levels of the IGP, but least over the west Indian and Himalayan foothill sites. The highly irregular granular aggregates (MISC) formed the second most abundant shape over the north Indian sites, containing metal rich particles indicating higher vehicular pollution/ industrial emissions over the cities of northern and western India (very significant at LKN and DDN). Such aggregates are higher in number in the aerosol samples collected in the bottom (mixed) layer, while their abundance reducing with altitude. The change in aerosol morphology specifically with respect to the presence of granular aggregate structures from the bottom to top layer (TL $>2 \mathrm{~km})$ is
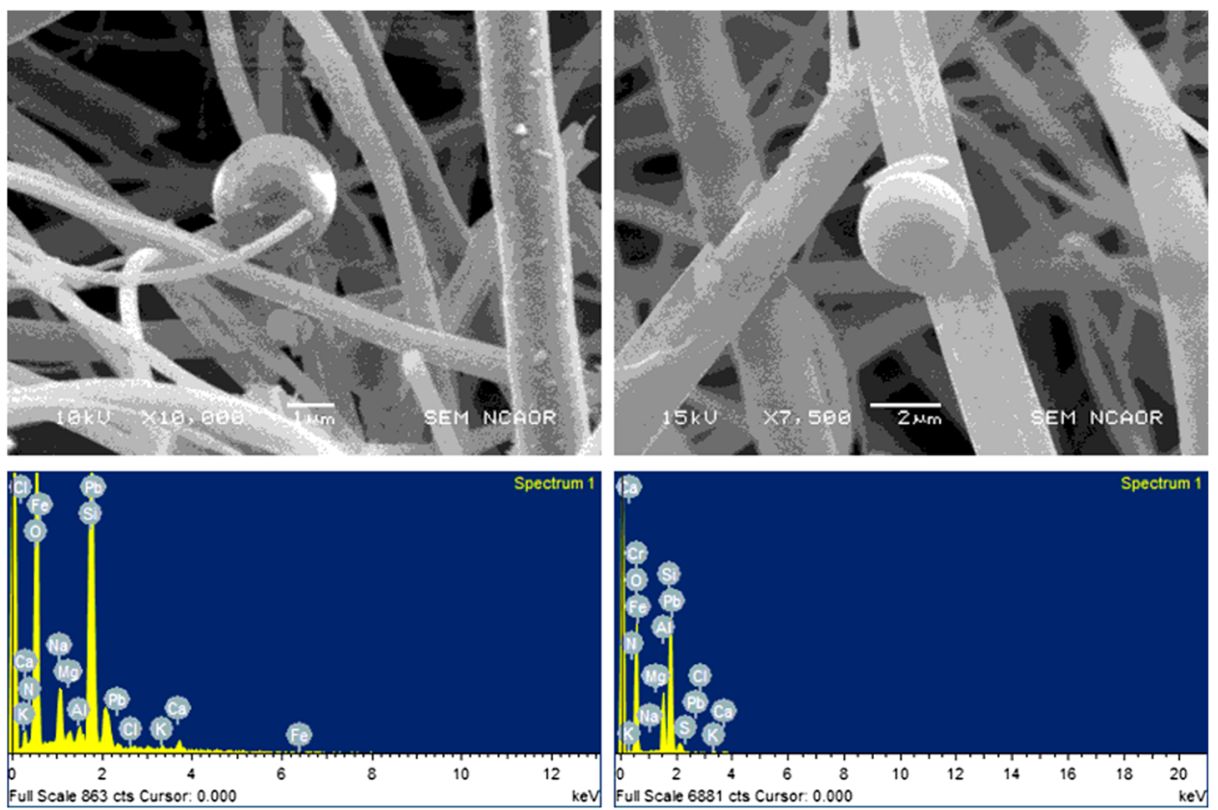

Fig. 5: Spherical smooth particles dominated with $\mathrm{N}$ and $\mathrm{O}$ 
Table 5. Weight $\%$ and Atomic\% of the elements corresponding to the spherical smooth aerosol particles shown in Fig. 5

\begin{tabular}{|c|c|c|c|c|c|}
\hline \multicolumn{3}{|c|}{ Sample-1 (spherical particle) } & \multicolumn{3}{|c|}{ Sample-2 (spherical particle) } \\
\hline Element & Weight\% & Atomic $\%$ & Element & Weight $\%$ & Atomic $\%$ \\
\hline $\mathbf{N}$ & 5.90 & 7.85 & $\mathbf{N}$ & 4.85 & 6.26 \\
\hline O & 61.54 & 71.77 & $\mathbf{O}$ & 66.86 & 75.59 \\
\hline $\mathrm{Na}$ & 2.72 & 2.21 & $\mathrm{Na}$ & 0.15 & 0.12 \\
\hline $\mathrm{Mg}$ & 0.50 & 0.38 & $\mathrm{Mg}$ & 0.02 & 0.02 \\
\hline $\mathrm{Al}$ & 0.54 & 0.38 & Al & 7.64 & 5.12 \\
\hline $\mathbf{S i}$ & 23.54 & 15.64 & $\mathbf{S i}$ & 19.27 & 12.41 \\
\hline $\mathrm{Cl}$ & 0.16 & 0.09 & $\mathrm{~S}$ & 0.11 & 0.06 \\
\hline $\mathrm{K}$ & 0.30 & 0.14 & $\mathrm{Cl}$ & 0.07 & 0.04 \\
\hline $\mathrm{Ca}$ & 1.17 & 0.55 & $\mathrm{~K}$ & 0.23 & 0.11 \\
\hline $\mathrm{Fe}$ & 2.73 & 0.91 & $\mathrm{Ca}$ & 0.18 & 0.08 \\
\hline \multirow[t]{2}{*}{$\mathrm{Pb}$} & 0.90 & 0.08 & $\mathrm{Fe}$ & 0.58 & 0.19 \\
\hline & & & $\mathrm{Pb}$ & 0.03 & 0.00 \\
\hline
\end{tabular}

highest over Jaipur (decreased from $23 \%$ to $15 \%$ ); however the pattern is opposite at JDR and NGP where the granular aggregate is higher in the TL (increased from $10 \%$ to $21 \%$ at JDR and $7 \%$ to $20 \%$ at NGP). This is indicative of the influence of synoptic air masses accumulating particles in the elevated region of the atmosphere over these locations. On the other hand, the percentage contribution of granular aggregates at LKN remains consistent $(\sim 30 \%)$ at both the levels, with increased amount in the TL at PTN.

(a)
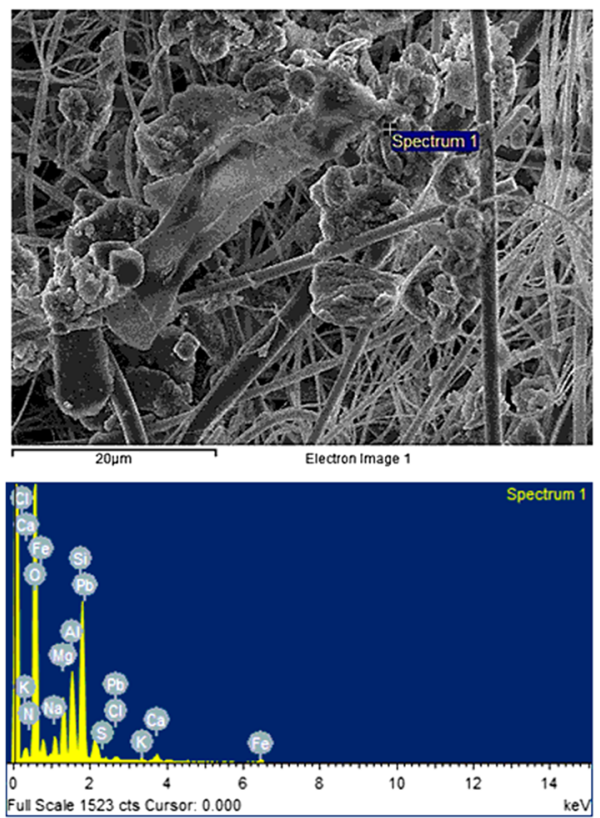

(b)
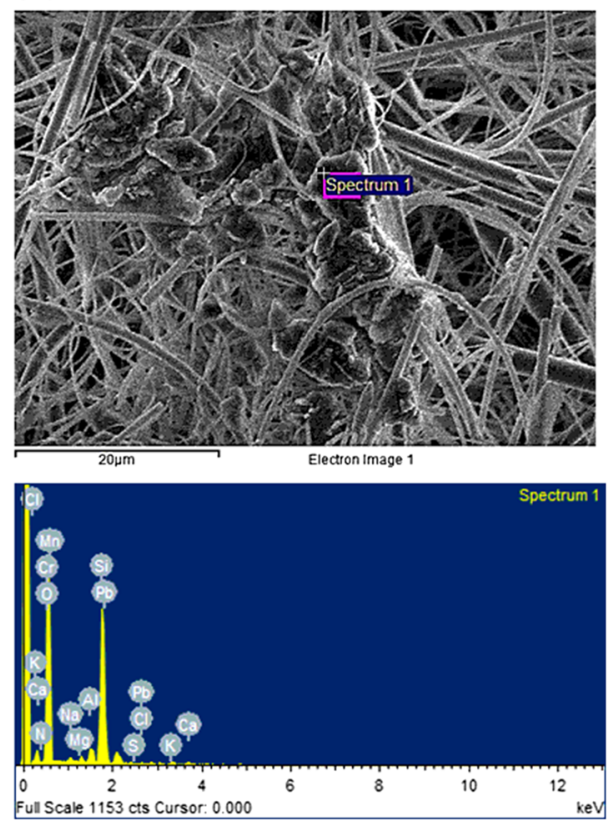

Fig. 6: (a) Metalliferous particles containing $\mathrm{Fe}$ (>13\% weight\%) along with $\mathrm{Al}$ and $\mathrm{Si}$; (b) Metalliferous particles containing $\mathrm{Cr}(>13 \%$ weight $\%)$ along with $\mathrm{Mn}$ and $\mathrm{Si}$ 
Table 6. Weight $\%$ and Atomic\% of the elements corresponding to the metalliferous particles shown in Fig. 6

\begin{tabular}{|c|c|c|c|c|c|}
\hline \multicolumn{3}{|c|}{ Sample-1 (irregular particle)) } & \multicolumn{3}{|c|}{ Sample-2 (irregular particle)) } \\
\hline Element & Weight\% & Atomic\% & Element & Weight $\%$ & Atomic\% \\
\hline $\mathrm{N}$ & 4.35 & 6.13 & $\mathrm{~N}$ & 7.60 & 13.17 \\
\hline $\mathrm{O}$ & 58.13 & 71.79 & $\mathrm{O}$ & 36.57 & 55.47 \\
\hline $\mathrm{Na}$ & 1.60 & 1.37 & $\mathrm{Na}$ & 0.26 & 0.27 \\
\hline $\mathrm{Mg}$ & 3.72 & 3.03 & $\mathrm{Mg}$ & 0.34 & 0.34 \\
\hline Al & 5.42 & 3.97 & $\mathrm{Al}$ & 0.92 & 0.82 \\
\hline $\mathbf{S i}$ & 11.21 & 7.88 & $\mathbf{S i}$ & 12.00 & 10.37 \\
\hline S & 0.06 & 0.04 & $\mathrm{~S}$ & 0.03 & 0.02 \\
\hline $\mathrm{Cl}$ & 0.28 & 0.15 & $\mathrm{Cl}$ & 0.21 & 0.15 \\
\hline K & 0.47 & 0.24 & $\mathrm{~K}$ & 0.47 & 0.29 \\
\hline $\mathrm{Ca}$ & 1.43 & 0.71 & $\mathrm{Ca}$ & 0.36 & 0.22 \\
\hline $\mathbf{F e}$ & 13.19 & 4.67 & $\mathrm{Cr}$ & 28.92 & 13.50 \\
\hline \multirow{2}{*}{$\mathrm{Pb}$} & 0.14 & 0.01 & Mn & 12.13 & 5.36 \\
\hline & & & $\mathrm{Pb}$ & 0.18 & 0.02 \\
\hline
\end{tabular}

The third most abundant shape of particles is the rectangular shape present particulary in the cities of HYD, JDR and PTN, where the dominance of rectangular rough (RR) particles is significant than the rectangular smooth (RS) particles. Triangular particles (both triangular smooth-TS and triangular rought-TR) are most abundant in the bottom layers of NGP and PTN, in addition to having the signatures of TR particles in the top layers of all the sites. At both Nagpur and Patna, a sharp decrease in the abundance of triangular particles from BL to TL (changing from $30 \%$ to $5 \%$ at Nagpur and $20 \%$ to $6 \%$ at PTN) are seen. As already mentioned, the triangular shaped particles in this study are observed to be associated with high concentrations of $\mathrm{Cr}$ and $\mathrm{Mn}$. Spherical shaped particles are abundant mainly over central part of India, along with their prominent presence at LKN and in the bottom layer of PTN.

\subsection{Quantification of elemental compositions}

To quantify the relative dominance of elemental components of aerosols, the weight $\%$ of individual elements are examined and shown as box and whisker plots in Fig. 8 for each of the distinct altitude zones of the observational sites.

The most abundant compound associated with the irregular rough particles is found to be $\mathrm{SiO}_{2}$ over all the sites (this is also evident from Table 3). Further, it is observed that $\mathrm{Cr}$ rich particles, followed by Mn (18-20\%), are dominated mostly in the bottom level. As already mentioned, the triangular particles are enriched in $\mathrm{Cr}$ and $\mathrm{Mn}$; rectangular rough particles are rich in $\mathrm{Cr}$ and $\mathrm{Ca}$; and spherical $\mathrm{N}$-rich particles are highly mixed with $\mathrm{Cr}$ and $\mathrm{Mn}$ and found abundant in the atmosphere of all the cities in both the vertical regions.

\subsubsection{Indo-Gangetic Plains}

Over the north Indian sites LKN and PTN in the IGP, the abundance of $\mathrm{SiO}_{2}$ is higher in the $\mathrm{TL}$ than that seen in the BL. Cr is found to remain consistent in both the levels over LKN, while the amount of $\mathrm{Mn}$ increases in TL. These are associated with highly irregular granular structure of the particles. Interestingly, $\mathrm{Cr}$ and $\mathrm{Mn}$ are absent in the TL over PTN. The enhancement of $\mathrm{SiO}_{2}$ at the upper region of $\mathrm{LKN}$ is consistent with the earlier measurements reported by Gogoi et al. (2019), in which it has been demonstrated that enhanced light 


\section{Bottom level (0.5-2.0 km) Top level (2.0-4.0 km)}
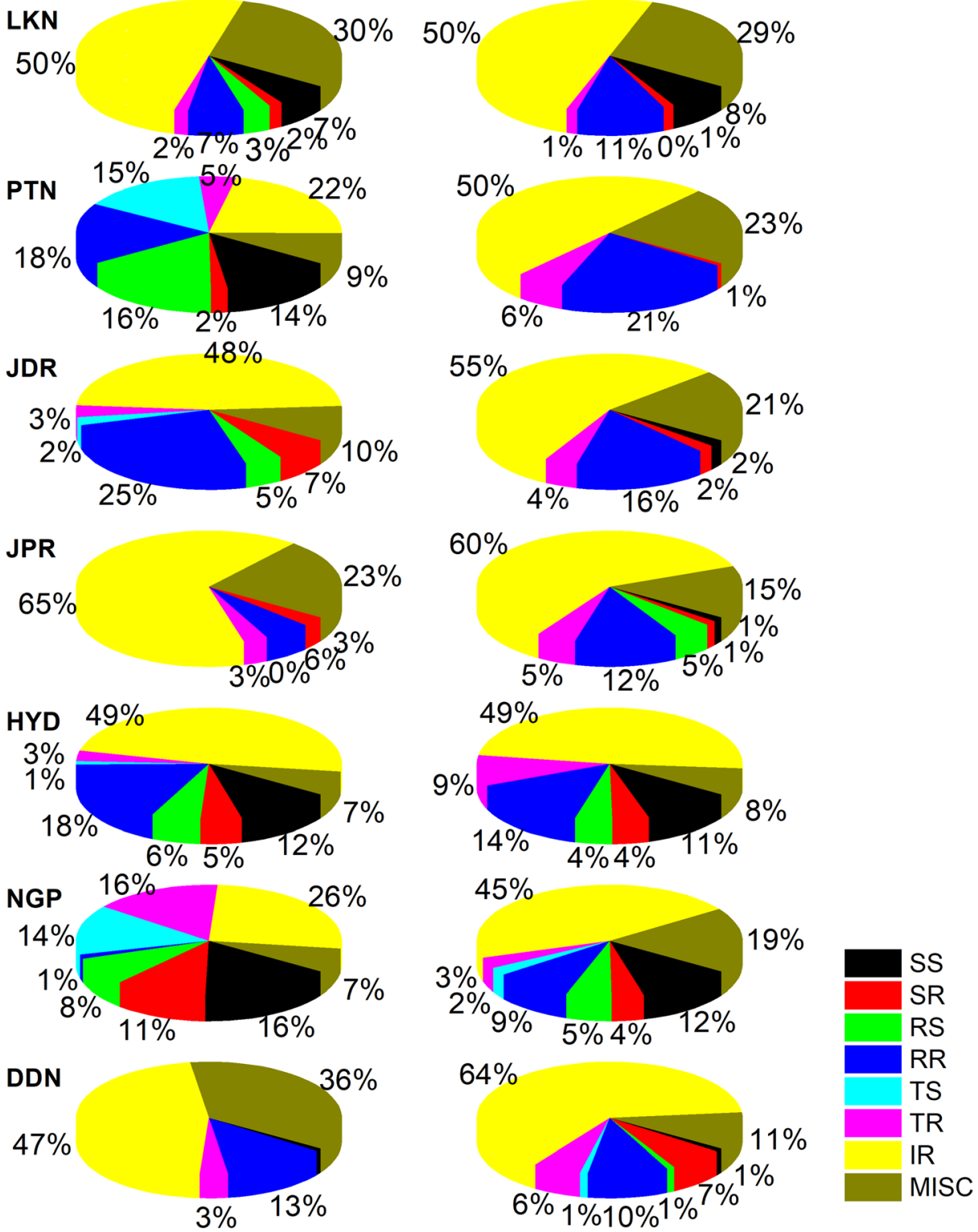

Fig. 7: Vertical distribution of the morphological structures of particles in two distinct altitude zones of the atmosphere over different geographic locations of India during spring-2013

absorption over the region is due to the presence of elevated coarse mode polluted dust. Similarly, the homogeneous distribution of carbon content in both BL and TL over LKN is consistent with the vertical profiles of smoke particles (derived from CALIPSO aerosol types) reported by Gogoi et al. (2019). 

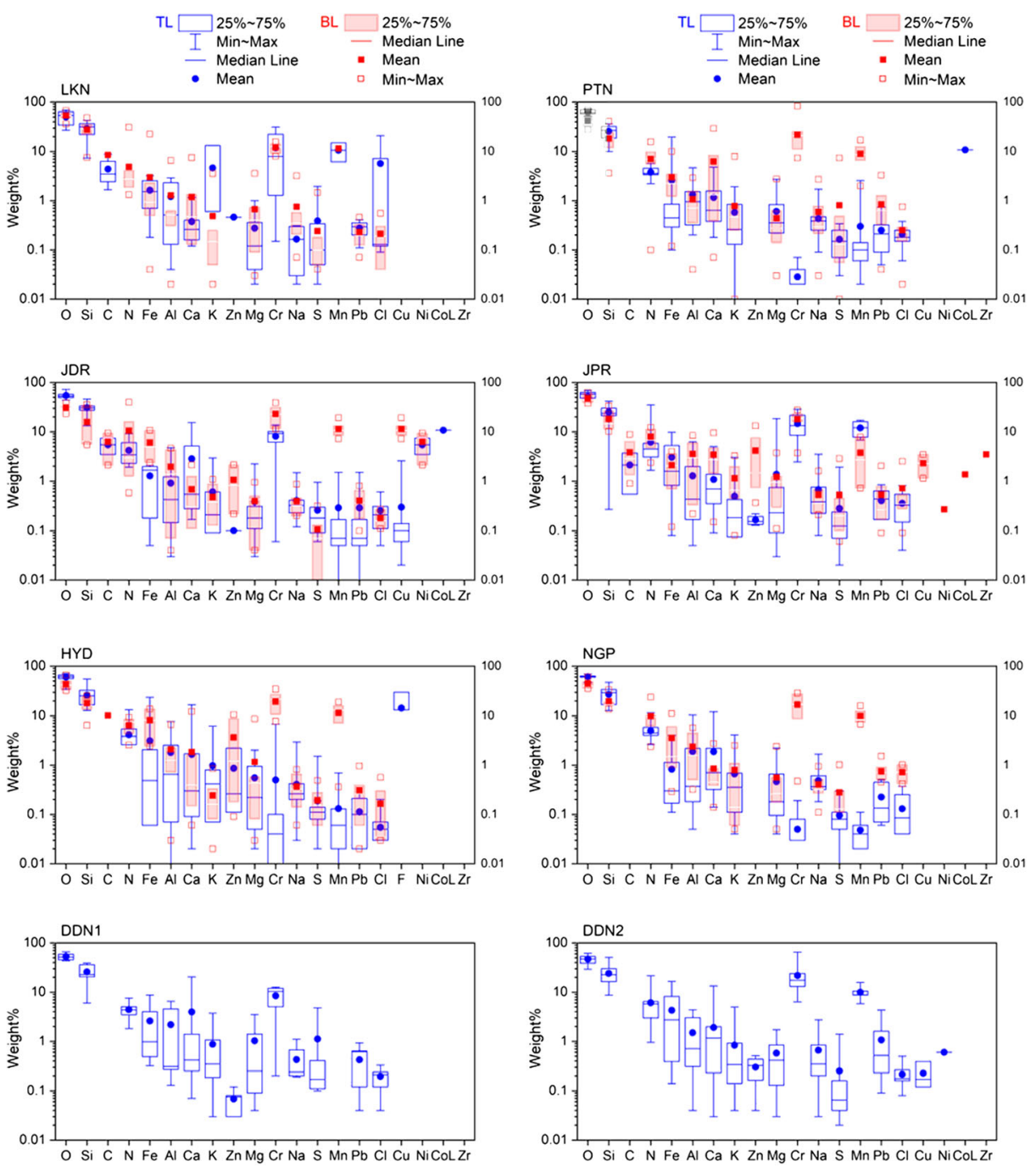

Fig. 8: Box and whisker plots of the weight\% of individual elements in the top and bottom layers of the atmosphere over distinct regions of India during spring-2013. Here, box denotes the 25 and 75 percentiles of the occurrences of a particular element. The minimum and maximum weight $\%$ are shown by the whisker for the top layer and by open red square for the bottom layer. DDN1 and DDN2 corresponds to the weight\% of TL observed on two different days

Located in the eastern part of the IGP, PTN is considered as the most populated city of state Bihar. Although no ores and metal processing industries are located at PTN, $\mathrm{Cr}$ and $\mathrm{Mn}$ are emitted in significant amounts from the wear and tear of tyres and smoke of vehicular traffic implying their presence in the BL. N-species are found to dominate the free tropospheric region of PTN. Fe content along with $\mathrm{N}$-species is also found in particles collected in the TL of PTN. 


\subsubsection{Western India}

In the city of JPR, Si forms a significant part of the the elemental composition with $25 \%$ in the BL and $18 \%$ in the TL. The second most important element found is $\mathrm{Cr}$ ( $18 \%$ in BL and $14 \%$ in TL). The abundant mineral deposits ocurring naturally in the area may be attributed to dominant production of Silica, Iron ore and Dolomite in the city, because a large part of the district is covered by a thick mantle of soil, blown and alluvium. Contrastingly, the Si content at JDR is nearly double $(\sim 30 \%)$ in the TL as compared to that in the BL $(\sim 15 \%)$. As the region is charecterized by sand dunes and wide stretches of sand, supplies significant amount of $\mathrm{SiO}_{2}$. The high winds during the sand storms in the area are capable of transporting the particles far beyond the $\mathrm{BL}$ into the free troposphere. Amounts of $\mathrm{Fe}, \mathrm{Al}$ and $\mathrm{Ca}$ are comparatively higher at JDR than JPR. Stone Processing is an important industry at JDr since geographically, it has access to materials such as Sandstone, Rhyolite, Dolomite, Limestone, Jasper and Granite (http://www.urbanemissions.info/india) used in the construction sector industry.

\subsubsection{Central India}

Over central India, the abundant spherical particles are found to be associated with $\mathrm{NaNO}_{3}$ and $\mathrm{CaNO}_{3}$ species mixed with $\mathrm{Fe}$ or $\mathrm{Al}$ (soil particles). Such non-crystalline particle morphologies are consistent with previous studies suggesting that drying of aqueous droplets can yield $\mathrm{NaNO}_{3}, \mathrm{Ca}\left(\mathrm{NO}_{3}\right)_{2}$ particles in an amorphous state (Wang and Laskin 2014 and references therein). At NGP, Cr decreases from $16 \%$ in the BL to nearly zero in the TL, similar to decrease in $\mathrm{Mn}$ from BL to TL. This is mainly attributed to the fact that more local sources like deposits of Coal, Manganese ore, Dolomite, Limestone, Iron Ore, Clay, Copper Ore, Chromite is abundant at NGP. It is also a supplier of sand from Kanhan river. The rural area of NPR is 645 sq. km as compared to the urban area of 217.17 sq.km (2001 census), which is characterized by the muddy, non-concrete roads supplying dust to the BL of the area. Thus, the locally produced elements are dominant near the surface than in the higher level of the atmosphere.

The close evaluation of the \% contribution of $\mathrm{N}$-species to the total elemental compostion revealed that the contribution is higher in the free troposphere over all the sties as compared to the $\mathrm{BL}$ indicating a long ragne transport of $\mathrm{NO}_{\mathrm{x}}$ species. It is observed to be $29 \%$ in the TL of HYD as compared to $10 \%$ in the BL of the city. Further, it is $11 \%$ in TL of LKN, while it is negligible (1\%) in the BL of the city. PTN and NGP also show similar observations. This could be because ammonia can react rapidly with sulfuric $\left(\mathrm{H}_{2} \mathrm{SO}_{4}\right)$ and nitric $\left(\mathrm{HNO}_{3}\right)$ and hydrochloric $(\mathrm{HCl})$ acids and can form secondary aerosols which are dominantly present in particles less than $2.5 \mu \mathrm{m}$ in diameter (Malm et al. 2004). These smaller particles can easily be lifted and transported to upper tropospheric levels as compared to large soil particles. Gases in its own form may also be transported faster to the upper levels where they can react with other fine dust particles. These ammonia rich fine particles have the capacity to alter the Earth's radiation budget both directly and indirectly (Warner et al. 2017 and references therein). The contribution of in situ sources might also affect these results. The sources may include lightening, aircraft emissions and strastopsheric intrusions. These uncertainties are difficult to estimate. Various models also predict the upper tropospheric transport processes of $\mathrm{NO}_{\mathrm{x}}$ with large uncertainties (Penner et al. 1998). 


\subsubsection{Himalayan foothills}

The Himalayan foothill site, DDN, is dominated by $\mathrm{SiO}_{2}$, but the percentage contribution of $\mathrm{SiO}_{2}$ to the total aerosol composition is less as compared to the other sites. However, presence of $\mathrm{Cr}$ and $\mathrm{Mn}$ is high at DDN. The lower abundance of $\mathrm{SiO}_{2}$, but presence of other minor elements seen at DDN is in line with the aerosol oncentrations and size distributions reported by Gogoi et al. (2019). Based on the observations carried out in two contrasting seasons of winter and spring, Gogoi et al. (2019) have reported that the vertical extent of particle concentrations are lower in spring than the winter season, where the presence of elevated (polluted) dust and smoke dominate the elevated region of DDN in winter. This is possibly due to an inversion created by the pushing down of downward flowing cold air from the top of the mountain by the warm air rising from the valley, thus stagnating the particles at higher altitude those were already advected from western desert or biomass burning sources prevailing during post-monsoon period.

\subsection{Comparitive analysis of the vertical and regional distribution of aerosols types}

Table 7 includes the major elements and Table 8 includes the minor elements and their relative abundance observed at different observational sites at two distinct altitude regimes of the atmosphere.

The free topopheric layer over the IGP shows higher silica rich particles (Table 7) as compared to the bottom layer. This observation suggests that there was dynamic mixing of air due to vertical air mass movements over the region which transported the coarser and heavier particles from the ground to the higher atmospheric layer $(>2 \mathrm{~km})$. This observation could also imply that since a dynamic force is driving the upward transport of dust particles from BL to TL, it could further transport the particles upwards to the himalayan foothills. Previous studies have reported that high altitude stations at the Himalayan foothills are affected by the aerosols originating from the polluted Indo-Gangetic plains and this can have precursions on the south Asian monsoon (Gautam et al. 2011; Brun et al. 2011; Hegde and Kawamura 2012). The same observation is made in the cities of central India where the particles are more silica rich in the upper layers. On the other hand, the Himalayan foothill site Dehradun depicted higher concentration of $\mathrm{SiO}_{2}$ in TL on first day. Towards the western part of northern India, the dominance of $\mathrm{SiO}_{2}$ in the $\mathrm{BL}$ and $\mathrm{TL}$ of the atmosphere are different; the elemental

Table 7. Weight $\%$ distribution of $\mathrm{SiO}_{2}$ (major elements) in the aerosols collected from two different height zones over the distinct Indian sites. Here, BL indicatesthe bottom layer (below $2.0 \mathrm{~km}$ ) and TL indicates the toplower (free-tropospheric layer above $2.0 \mathrm{~km}$ )

\begin{tabular}{llll}
\hline Region/ Cities & Major element & $\%(\mathrm{BL})$ & $\%(\mathrm{TL})$ \\
\hline $\begin{array}{l}\text { North India (IGP) } \\
\text { Lucknow }\end{array}$ & $\mathrm{SiO}_{2}$ & 79 & 81 \\
$\quad$ Patna & $\mathrm{SiO}_{2}$ & 60 & 89 \\
West-India & $\mathrm{SiO}_{2}$ & 47 & 85 \\
$\quad$ Jodhpur & $\mathrm{SiO}_{2}$ & 85 & 77 \\
$\quad$ Jaipur & $\mathrm{SiO}_{2}$ & & 71 (day-1), 19 (day-2) \\
Himalayan-Foothill & $\mathrm{SiO}_{2}$ & & 86 \\
$\quad$ Dehradun & $\mathrm{SiO}_{2}$ & 61 & 88 \\
Central India & & 64 & \\
Hyderabad & & & \\
Nagpur & & &
\end{tabular}


Table 8. Percentage distribution of the minor elements in the aerosols collected from two different height zones over the distinct Indian sites

\begin{tabular}{|c|c|c|c|c|}
\hline Cities & Minor elements (BL) & $\%(\mathrm{BL})$ & Minor elements (TL) & $\%(\mathrm{TL})$ \\
\hline \multicolumn{5}{|c|}{ North India (IGP) } \\
\hline Lucknow & $\mathrm{Cr}, \mathrm{Mn}$ & 21 & $\mathrm{Cr}, \mathrm{Mn}$ & 19 \\
\hline Patna & $\mathrm{Cr}, \mathrm{Mn}$ & 40 & $\mathrm{~N}, \mathrm{Fe}$ & 11 \\
\hline \multicolumn{5}{|l|}{ West-India } \\
\hline Jodhpur & $\mathrm{Cr}, \mathrm{Mn}$ & 53 & $\mathrm{Cr}$ & 15 \\
\hline Jaipur & $\mathrm{Cr}$ & 15 & $\mathrm{Cr}, \mathrm{Mn}$ & 53 \\
\hline \multicolumn{5}{|c|}{ Himalayan-Foothill } \\
\hline Dehradun & & & $(\mathrm{Ca}, \mathrm{Cr})$ day-1; $\quad(\mathrm{Cr}, \mathrm{Ma})$ day -2 & 29 (day-1); 81 (day-2) \\
\hline \multicolumn{5}{|l|}{ Central India } \\
\hline Hyderabad & $\mathrm{Cr}, \mathrm{Mn}$ & 39 & $\mathrm{~N}, \mathrm{Fe}$ & 14 \\
\hline Nagpur & $\mathrm{Cr}, \mathrm{Mn}, \mathrm{N}$ & 36 & $\mathrm{~N}, \mathrm{Ca}$ & 18 \\
\hline
\end{tabular}

composition (dominance of Si in TL) at JDR is somewhat similar to that observed at the central Indian sites.

Unlike the major elements, the minor elements (Table 8) $\mathrm{Cr}$ and $\mathrm{Mn}$ (rich in smaller triangular or rectangular shape particles, as shown in Fig. 4) did not show significant abundance in the free-troposheric layer of the IGP. However, JPR and DDN are an exception to this observation. A possible explanation to the observation at DDN could be related to the orography of the region, where fine particles can be uplifted easily over the hill slopes as compared to the heavier $\mathrm{SiO}_{2}$ particles.

\subsection{Chemical characteristics}

To have deeper insight into the distinct source processes and types of aerosols, distributed over twoverticalregions of the atmosphere, the bulk analysis of the aerosols was carried out by analysing the major water soluble cations $\left(\mathrm{Na}^{+}, \mathrm{NH}_{4}^{+}, \mathrm{Mg}^{2+}, \mathrm{K}^{+}, \mathrm{Ca}^{2+}\right.$; Fig. 9) and major water soluble anions $\left(\mathrm{Cl}^{-}, \mathrm{SO}_{4}{ }^{2-}, \mathrm{NO}_{3}{ }^{-}\right.$; Fig. 10) for each of the distinct geographic regions. The relative \% contributions of $\mathrm{Na}^{+}, \mathrm{Ca}^{2+}, \mathrm{NO}_{3}{ }^{-}$and $\mathrm{SO}_{4}{ }^{2-}$ are significantly higher in the total mass concentrations of the ions in the aerosols.

The Fig. 9 shows that the relative dominance of $\mathrm{Ca}^{2+}$ is higher in the TL as compared to $\mathrm{BL}$, regionally which reduces significantly from the highest abundance at JDR to the lowest at HYD. The relative dominance of $\mathrm{Ca}^{2+}$ and $\mathrm{Na}^{+}$can be attributed to local soil/crustal sources. The dominance of $\mathrm{Ca}^{2+}$ in the TL highlighted the importance of dust being transported from distant sources. This observation is consistent with the results of the EDS analysis where \% contribution of $\mathrm{SiO}_{2}$ (indicator of dust) is found to be higher in the TL as compared to $\mathrm{BL}$ (section 3.3). The presence of $\mathrm{Ca}^{2+}$ in the TL indicates transport of dust from the great Indian desert in north-western India (e.g., Brooks et al. 2019). However the individual particle analysis (Fig. 8) suggests that the elemental contribution of $\mathrm{Ca}$ (mean weight\%) is higher in the BL over LKN, PTN, and JPR, though comparable at HYD. This varying observations could be attributed to the fact that only the water soluble $\mathrm{Ca}^{2+}$ is assessed in the ion chromatography technique. Morevover, the study sites are predominantly affected by crustal contributions; most likely the $\mathrm{Ca}^{2+}$ is present as $\mathrm{CaCO}_{3}$ in the aerosols which forms the insoluble part of $\mathrm{Ca}^{2+}$, hence cannot be fully quantified by the present IC analysis.

Contrastingly $\mathrm{Na}^{+}$shows highest abundance at HYD and lowest in the BL at JDR. $\mathrm{Na}^{+}$however could be sourced from either sea salt or crustal sources. Therefore the $\%$ contribution of $\mathrm{ssNa}^{+}$to the 
(a) Bottom Layer (BL) Top Layer (TL)

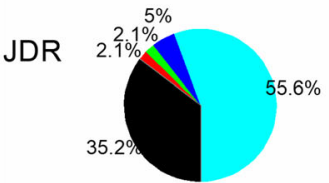

JPR

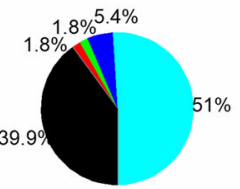

LKN

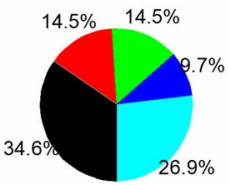

PTN

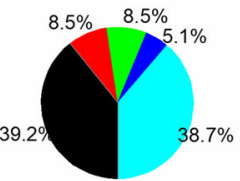

NGP

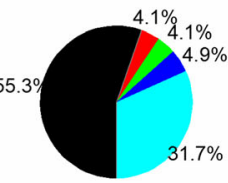

HYD

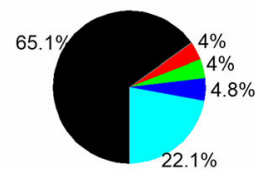

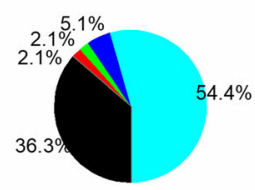
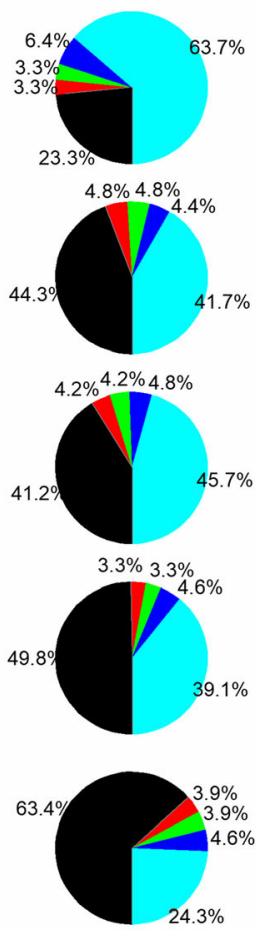

(b)
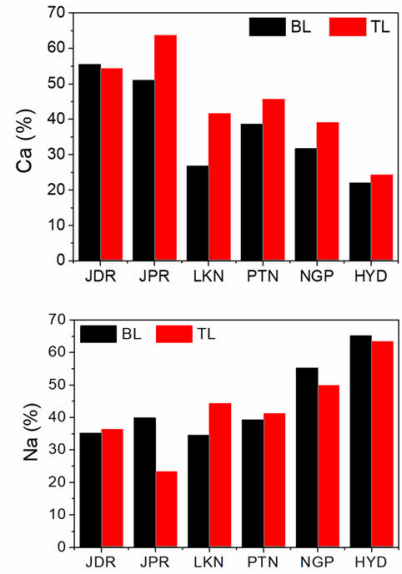

(c) $\%$ Contribution of sea salt to total $\mathrm{Na}^{+}$

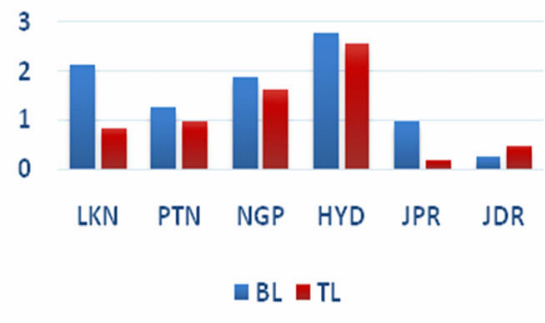

Fig. 9: (a) Relative dominance of major cations $\left(\mathrm{Na}^{+}, \mathrm{NH}_{4}^{+}, \mathrm{K}^{+}, \mathrm{Mg}^{2+}\right.$ and $\left.\mathrm{Ca}^{2+}\right)$ at two distinct altitude zones over the observational sites. (b) The regional features of the relative dominance of $\mathrm{Ca}^{2+}$ and $\mathrm{Na}^{+}$occurring over the arid regions of north-western India, through IGP to the central parts of India are also shown. (c) \% contribution of ssNa+ to the total $\mathrm{Na}^{+}$mass concentration in the aerosols at two vertical zones over the different Indian cities.

total $\mathrm{Na}^{+}$was estimated using the equation-1(Virkkula et al. 2006).

$$
\mathrm{ssNa}^{+}=\left(\mathrm{R}_{\mathrm{c}} \cdot \mathrm{Na}^{+}-\mathrm{Ca}^{2+}\right) /\left(\mathrm{R}_{\mathrm{c}}-\mathrm{R}_{\mathrm{m}}\right)
$$

where, $\mathrm{R}_{\mathrm{m}}$ and $\mathrm{R}_{\mathrm{c}}$ are the mean ratios of $\mathrm{Ca}^{2+} / \mathrm{Na}^{+}$in the marine aerosols and $\mathrm{Ca}^{2+} / \mathrm{Na}^{+}$ratio in the crust respectively. The values of $\mathrm{Ca}^{2+} / \mathrm{Na}^{+}$in the marine $\left(\mathrm{R}_{\mathrm{m}}\right)$ and crust $\left(\mathrm{R}_{\mathrm{c}}\right)$ aerosol are assumed to be 0.038 and 1.78 (Bowen 1979). It is found that the relative contibution of ssNa+ to the total $\mathrm{Na}^{+}$was $<3 \%$ for all the cities (Fig. 9c), clearly indicating a crustal source for $\mathrm{Na}^{+}$over the Indian cities. This observation further supports the dominance of irregular particles $\left(\mathrm{SiO}_{2}\right.$ particles) in the $\mathrm{BL}$ and $\mathrm{TL}$ over all the study sites. The high non sea-salt component of $\mathrm{Na}^{+}$and the presence of $\mathrm{Ca}^{2+}$ as $\mathrm{CaCO}_{3}$ is supported by the fact that the Indo Gangetic alluvial plain (specifically northwestern part of IGP) is characterized by high $\mathrm{pH}$ of sodic soils having high content of $\mathrm{CaCO}_{3}$ and sodium present as carbonates (Pal et al. 2003). The highest contribution of sea salt, $2.8 \%$ in the BL of HYD indicates 
(a) Bottom Layer (BL) Top Layer (TL)
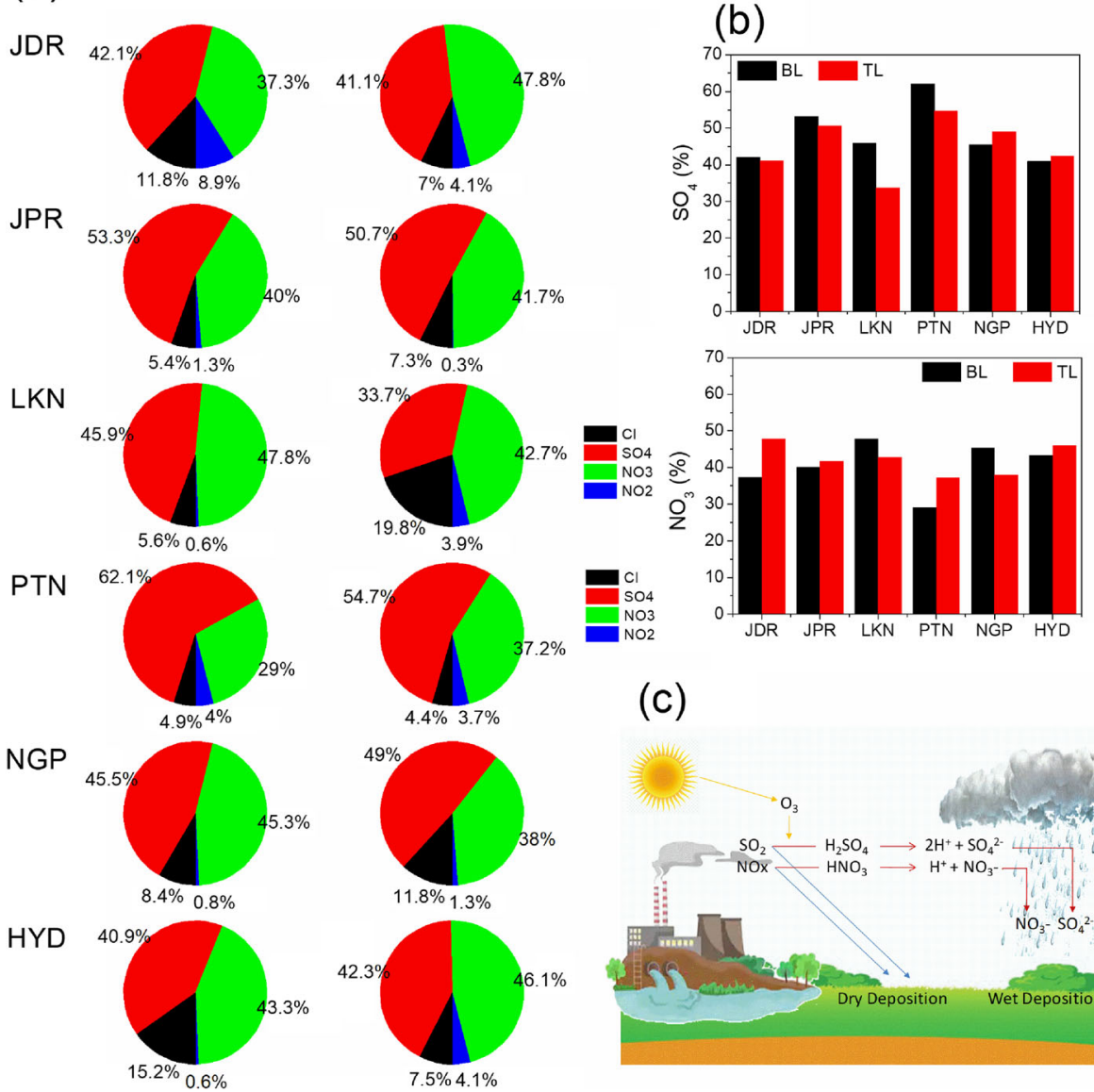

HYD
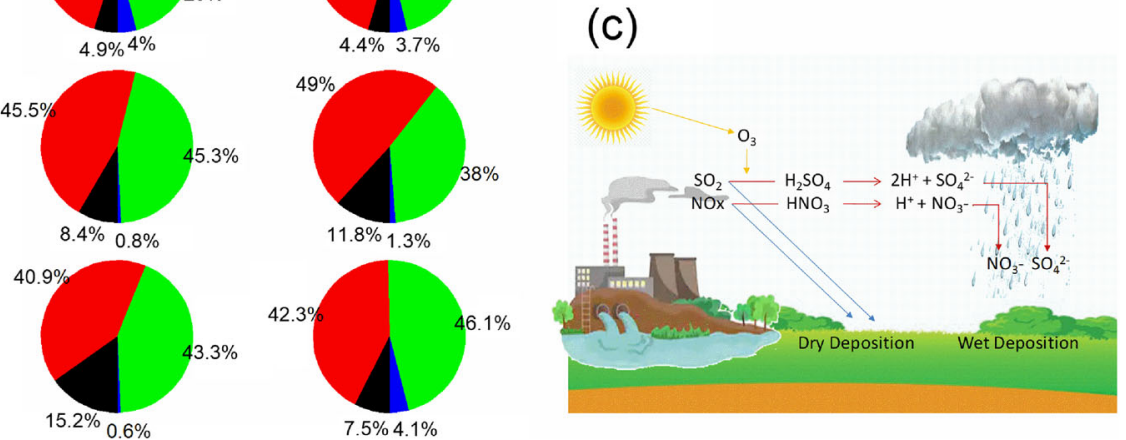

Fig. 10: (a) Relative dominance of major anions $\left(\mathrm{Cl}^{-}, \mathrm{SO}_{4}{ }^{2-}, \mathrm{NO}_{3}{ }^{-}, \mathrm{NO}_{2}{ }^{-}\right)$at two distinct altitude zones over the observational sites of India. (b) Regional distinctiveness of the relative dominance of $\mathrm{SO}_{4}{ }^{2-}$ and $\mathrm{NO}_{3}{ }^{-}$occurring over the arid regions northwestern India, through IGP to the central parts of India are shown. (c) A schematic representation of the sulphur cycle over land.

highly varying sources of $\mathrm{Na}^{+}$. Higher percentage contribution of total $\mathrm{Na}^{+}$and low $\mathrm{ssNa}^{+}$ contribution in the total aerosol mass concentration, especially in the top layer, is indicative that long range transport of dust from the north western region (Thar desert). This observation stands important because it can alter the single scattering albedo of the aerosols. Previous study of Babu et al. (2016) carried out in northern India during spring have shown that SSA increases with altitude in the atmospheric column.

Relative abundance of $\mathrm{SO}_{4}{ }^{2-}$ (Fig. 10) is found to be highest in the $\mathrm{BL}$ of the eastern IGP site PTN. Comparing the latitudinal variation of $\mathrm{SO}_{4}{ }^{2-}$ over different cities, the relative \% contribution of $\mathrm{SO}_{4}{ }^{2-}$ to the anionic mass is higher in $\mathrm{BL}$ of the IGP locations. However, the cities like HYD and NGP which lie outside the IGP, the \% relative contribution of $\mathrm{SO}_{4}{ }^{2-}$ is higher in the TL. High $\mathrm{SO}_{4}{ }^{2-}$ loading in the free troposphere suggests additional impact of the long range anthropogenic/industrial pollution affecting the high altitude aerosols over these cities. Presence of high sulphate in the free tropospheric aerosols could alter the scattering 
properties of aerosols and hence aerosol optical depth (AOD). On the other hand, $\mathrm{NO}_{3}{ }^{-}$ abundance remains nearly consistent over all the locations. Further, $\mathrm{SO}_{2}$ sourced from various anthropogenic activities like coal buring, industrial emissions and vehicular combustions undergo various processes of nucleation, condensation, coagulation, leading to formation and growth of new particles in the atmosphere. The mass ratio $\mathrm{NO}_{3}{ }^{-} / \mathrm{SO}_{4}{ }^{2-}$ thus provides useful information about the influence of the stationary (coal combustion or biomass burning) and mobile (e.g., vehicular emissions) sources of sulfur and nitrogen (Arimoto et al. 1996; Yao et al. 2002). In the present study, $\mathrm{NO}_{3}{ }^{-} / \mathrm{SO}_{4}{ }^{2-}$ ratio ranged from 0.46 to 1.26 , having ratios $>1$ in the free-tropospheric region (TL) of LKN, NGP and JDR and lowest in the mixed layer (BL) of HYD $(\sim 0.46)$. This indicates that the vehicular emissions significatnly affect the free tropospheric regions of LKN, NGP and JDR more strongly than other places. Also, these observations suggest that the boundary layer of most cities of the IGP is influenced by the stationary aeorsol sources like coal or fossil fuel burning or power plants etc. All the above observations are in line with the morphological characteristics as seen from SEM and EDS data. Significanly higher abundance of $\mathrm{SO}_{4}{ }^{2-}$ and $\mathrm{NO}_{3}{ }^{-}$species in the atmosphere pose various climatic concerns (as indicated by the schematic in Fig. 10).

\subsection{Possible climatic implications}

Mineral particles like $\mathrm{CaCO}_{3}$ are generally internally mixed or react with acid containing gases like $\mathrm{H}_{2} \mathrm{SO}_{4}$ or $\mathrm{HNO}_{3}$ which are termed as "secondary acids". The reaction would result in the formation of either $\mathrm{Ca}\left(\mathrm{NO}_{3}\right)_{2}$ or $\mathrm{CaSO}_{4}$. In the present study, since $\mathrm{N}$ signal dominates the entire sample set in all the cities clearly indicates that $\mathrm{Ca}\left(\mathrm{NO}_{3}\right)_{2}$ was formed in the atmosphere, along with other nitrate compounds such as $\mathrm{NaNO}_{3}$. Such reactions could have displaced $\mathrm{Cl}^{-}$as seen by the low weight $\%$ of elemental $\mathrm{Cl}$ and also $\mathrm{Cl}^{-}$(bulk analysis) in all the aerosol particles. $\mathrm{NaNO}_{3}$ and $\mathrm{Ca}\left(\mathrm{NO}_{3}\right)_{2}$ can retain water and remain in a metastable state at very low relative humidity (Wang and Laskin 2014). However, when mixed with organics or metal species they may lose their shape and hygrocopicity which can directly effect their radiative properties and hence can have an indirect impact on the climate.

Apart from elemental compositions, particulate size and morphology are crucial parameters to consider while quantifying the effect of aerosols on radiation. Based on various model and radiative transfer simulations, several investigators have reported the uncertainties arising out of the spherical considerations of non-spherical particles. For example, Li et al. (2014) have reported that the negligence of non-spherical nature of particles can have severe influence on AOD retrievals from satellite, largely due to the deviations in derived phase function of nonspherical particles under spherical assumptions. Similarly, spherical shape assumption for dust in the retrieval of AOD using OMAERUV algorithm showed $20 \%$ difference (lower) to AERONET and MODIS AODs (Gassó and Torres 2016). These examples suggest the requirement of a representative atmospheric aerosol model considering the nature of dustlike non-spherical aerosols, other than Mie calculation, for the development of accurate aerosol inversion algorithms. As the spherical assumption of an arbitrary shape and hence the estimation of aerosol optical properties vary largely from the actual properties of the target material, this leads to large biases in the estimation of aerosol radiative properties. Since the percentage share of spherical smooth or rough particles are highly subdued $(<10 \%)$ over the Indian region, spherical assumption of a large share of non-spherical particles, especially dominant over the IGP, needs to be investigated in detail. 


\section{Summary and conclusions}

The present study critically assesses the relevant knowledge pertaining to the vertical distributions of the morphological features of aerosols during the spring time over different regions of India. This information is crucial for the accurate estimation of aerosol radiative properties over the IGP. The main findings of the study include:

1. The spring-time aerosols prevailing over the Indian region are found to possess various shapes and sizes, which are associated with distinct elemental compositions, possess regional distinctiveness and vertical gradients.

2. Irregular rough (IR) particles are found to dominate over all the sites irrespective of the sampling height, while that of highly irregular granular aggregates formed the second most abundant shape over the north Indian sites. Such aggregates indicate the processes of coagulation and coalescence in the urban cities. Such processes of restructuring of aerosol particles could considerably effect the radiative properties of aerosols

3. Fine $(<2 \mu \mathrm{m})$ spherical particles composed of $\mathrm{Na}, \mathrm{Ca}$ (traces of $\mathrm{Fe}, \mathrm{Al}$ ) are found in the free troposphere of both the IGP and Central India. $\mathrm{Na}$ and $\mathrm{Ca}$ in these particles could be present as $\mathrm{NaNO}_{3}$ and $\mathrm{Ca}\left(\mathrm{NO}_{3}\right)_{2}$ owing to the high $\mathrm{N}$ and $\mathrm{O}$ content in these particles. The knowledge of mixing state of aerosol is critical for the estimation and understanding of light scattering, water uptake, particle acidity, and aerosol chemistry which have a direct impact on the climate

4. Vertical distributions of the ionic composition of aerosols over the IGP and central Indian cities demonstrate higher contributions of anthropogenic $\left(\mathrm{SO}_{4}{ }^{2-}\right)$ and crustal components $\left(\mathrm{Ca}^{2+}\right.$ and $\left.\mathrm{nssNa}^{+}\right)$to free tropospheric layer.

5. In view of the abundant non-spherical particulate distribution over India during spring, accurate information on arbitrarily shaped, inhomogeneous and anisotropic particles need to consider for generating representative region specific atmospheric aerosol models as well as developing improved satellite algorithms. The data generated in the present study forms a baseline to conduct similar efforts in future covering different seasons and distinct vertical levels of the atmosphere. A detailed investigation is required to understand the connections and dependencies between the morphological and radiative properties of aerosols for accurately assessing the climatic implications of aerosols. The lack of such an information reflects large uncertainties in the studies focussing only on the physicochemical and optical properties of aerosol particles. Modeling efforts are needed to better understand the role of aerosol morphology and internal mixing at the single-particle level on the radiative forcing and other climate-relevant properties of aerosols .

Acknowledgements This study was carried out as part of the Regional Aerosol Warming Experiment (RAWEX) under the Aerosols and Radiative Forcing over India (ARFI) project of ISRO-Geosphere Biosphere Program (ISRO-GBP). We acknowledge National Remote Sensing Centre (NRSC), Hyderabad for the support with the aircraft operation and measurements. The authors SG and RM thank the Director, NCPOR and Ministry of Earth Sciences for the support and encouragement to the Electron Microscopy facilities at NCPOR, Goa. We acknowledge the kind support of Dr. Thamban Meloth, NCPOR for providing the analytical facilities for carrying out ionic analysis of aerosol samples. The help of Ashish Painginkar, NCPOR is humbly acknowleged throughout the IC analysis. 


\section{References}

Adachi, K., Tainosho, Y.: Characterization of heavy metal particles embedded in tire dust. Environ. Int. 30, 10091017 (2004). https://doi.org/10.1016/j.envint.2004.04.004

Agrawal, A., Upadhyay, V.K., Sachdeva, K.: Study of aerosol behavior on the basis of morphological characteristics during festival events in India. Atmos. Environ. 45, 3640-3644 (2011). https://doi.org/10.1016/j. atmosenv.2011.04.006

Arimoto, R., Duce, R.A., Savoie, D.L., Prospero, J.M., Talbot, R., Cullen, J.D., Tomza, U., Lewis, N.F., Ray, B.J.: Relationships among aerosol constituents from Asia and the North Pacific during PEM-west a. Journal of Geophysical Research Atmospheres. 101, 2011-2023 (1996). https://doi.org/10.1029/95JD01071

Babu, S.S., Nair, V.S., Gogoi, M.M., Krishna Moorthy, K.: Seasonal variation of vertical distribution of aerosol single scattering albedo over Indian sub-continent: RAWEX aircraft observations. Atmos. Environ. 125, 312-323 (2016). https://doi.org/10.1016/j.atmosenv.2015.09.041

Bowen, H.J.M.: Environmental Chemistry of the Elements. Elsevier, New York (1979)

Brooks, J., Allan, J.D., Williams, P.I., Liu, D., Fox, C., Haywood, J., Langridge, J.M., Highwood, E.J., Kompalli, S.K., O’Sullivan, D., Babu, S.S., Satheesh, S.K., Turner, A.G., Coe, H.: Vertical and horizontal distribution of submicron aerosol chemical composition and physical characteristics across northern India during premonsoon and monsoon seasons. Atmos. Chem. Phys. 19, 5615-5634 (2019). https://doi.org/10.5194/acp$19-5615-2019$

Brun, J., Shrestha, P., Barros, A.P.: Mapping aerosol intrusion in Himalayan valleys using the moderate resolution imaging Spectroradiometer (MODIS) and cloud-aerosol Lidar and infrared pathfinder satellite observation (CALIPSO). Atmos. Environ. 45, 6382-6392 (2011). https://doi.org/10.1016/j.atmosenv.2011.08.026

Choěl, M., Deboudt, K., Osán, J., Flament, P., Van Grisken, R.: Quantitative determination of low-Z elements in single atmospheric particles on boron substrates by automated scanning electron microscopy-energydispersive X-ray spectrometry. Anal. Chem. 77, 5686-5692 (2005). https://doi.org/10.1021/ac050739x

Gassó, S., Torres, O.: The role of cloud contamination, aerosol layer height and aerosol model in the assessment of the OMI near-UV retrievals over the ocean. Atmospheric Measurement Techniques. 9, 3031-3052 (2016). https://doi.org/10.5194/amt-9-3031-2016

Gautam, R., Hsu, N.C., Tsay, S.C., Lau, K.M., Holben, B., Bell, S., Smirnov, A., Li, C., Hansell, R., Ji, Q., Payra, S., Aryal, D., Kayastha, R., Kim, K.M.: Accumulation of aerosols over the indo-Gangetic plains and southern slopes of the Himalayas: distribution, properties and radiative effects during the 2009 premonsoon season. Atmos. Chem. Phys. 11, 12841-12863 (2011). https://doi.org/10.5194/acp-11-12841-2011

Gogoi, M. M., Lakshmi, N. B., Nair, V. S., Kompalli, S. K., Moorthy, K. K., \& Babu, S. S. (2019). Seasonal Contrast in the Vertical Profiles of Aerosol Number Concentrations and Size Distributions over India: Implications from RAWEX aircraft campaign. Journal of Earth System Science. https://doi.org/10.1007 /s12040-019-1246-y

Gupta, P., Satsangi, M., Satsangi, G.P., Jangid, A., Liu, Y., Pani, S.K., Kumar, R.: Exposure to respirable and fine dust particle over north-Central India: chemical characterization, source interpretation, and health risk analysis. Environ. Geochem. Health. (2019). https://doi.org/10.1007/s10653-019-00461-w

Hegde, P., Kawamura, K.: Seasonal variations of water-soluble organic carbon, dicarboxylic acids, ketocarboxylic acids, and $\alpha$-dicarbonyls in central Himalayan aerosols. Atmos. Chem. Phys. 12, 66456665 (2012). https://doi.org/10.5194/acp-12-6645-2012

Jayachandran V., Babu, S.S., Vaishya, A., Gogoi, M.M., Nair, V.S., Satheesh, S.K. \& Moorthy, K.K. (2020). Altitude profiles of $\mathrm{CCN}$ characteristics across the indo-Gangetic plain prior to the onset of the Indian summer monsoon. Atmospheric Chemistry and Physics, 10.5194/acp-20-561-2020, 2020

Kotas, J., Stasicka, Z.: Chromium occurrence in the environment and methods of its speciation. Environ. Pollut. 107, 263-283 (2000). https://doi.org/10.1016/S0269-7491(99)00168-2

Kumar, R., Srivastava, S.S. \& Kumari, K.M. (2007). Characteristics of Aerosols over Suburban and Urban Site of Semiarid Region in India: Seasonal and Spatial Variations. Aerosol and Air Quality Research, https://oi. org/10.4209/aaqr.2007.02.0010

Kumar, R. \& Kumari, K.M. (2015). Aerosols and Trace Gases Characterization over Indo-Gangetic Plain in Semiarid Region. Urban Climate, https://doi.org/10.1016/j.uclim.2014.12.001

Laskin, A., Cowin, J.P., Iedema, M.J.: Analysis of individual environmental particles using modern methods of electron microscopy and X-ray microanalysis. J. Electron Spectrosc. Relat. Phenom. 150, 260-274 (2006). https://doi.org/10.1016/j.elspec.2005.06.008

Li, C., Xue, Y., Huene, W.H., Zhang, J., Pan, P.: Quantitative evaluation of uncertainties in satellite retrieval of dust-like aerosols induced by spherical assumption. J. Quant. Spectrosc. Radiat. Transf. 136, 45-57 (2014). https://doi.org/10.1016/j.jqsrt.2014.01.003 
Malm, W.C., Schichtel, B.A., Pitchford, M.L., Ashbaugh, L.L., Eldred, R.A.: Spatial and monthly trends in speciated fine particle concentration in the United States. Journal of Geophysical Research D: Atmospheres. 109, (2004). https://doi.org/10.1029/2003JD003739

Nair, V.S., Babu, S.S., Gogoi, M.M., Moorthy, K.K.: Large-scale enhancement in aerosol absorption in the lower free troposphere over continental India during spring. Geophys. Res. Lett. 43, 11,453-11,461 (2016). https://doi.org/10.1002/2016GL070669

Pachauri, T., Singla, V., Satsangi, A., Lakhani, A., Maharaj Kumari, K.: SEM-EDX characterization of individual coarse particles in Agra, India. Aerosol and Air Quality Research. 13, 523-536 (2013). https://doi. org/10.4209/aaqr.2012.04.0095

Padmakumari, B., Maheskumar, R.S., Anand, V., Axisa, D.: Microphysical characteristics of convective clouds over ocean and land from aircraft observations. Atmos. Res. 195, 62-71 (2017). https://doi.org/10.1016/j. atmosres.2017.05.011

Pal, D.K., Srivastava, P., Durge, S.L., Bhattacharyya, T.: Role of microtopography in the formation of sodic soils in the semi-arid part of the indo-Gangetic Plains. India. Catena. 51, 3-31 (2003). https://doi.org/10.1016 /S0341-8162(02)00092-9

Penner, J.E., Bergmann, D.J., Walton, J.J., Kinnison, D., Prather, M.J., Rotman, D., Price, C., Pickering, K.E., Baughcum, S.L.: An evaluation of upper troposphere NOx with two models. Journal of Geophysical Research Atmospheres. 103, 22097-22113 (1998). https://doi.org/10.1029/98JD01565

Pipal, A.S., Kulshrestha, A., Taneja, A.: Characterization and morphological analysis of airborne PM2.5 and PM10 in Agra located in north Central India. Atmospheric Environment. (2011). https://doi.org/10.1016/j. atmosenv.2011.03.062

Sachdeva, K., Attri, A.K.: Morphological characterization of carbonaceous aggregates in soot and free fall aerosol samples. Atmos. Environ. 42, 1025-1034 (2008). https://doi.org/10.1016/j.atmosenv.2007.10.002

Singh, A. K., Srivastava, M. K., Singh, M., Srivastava, A., Kumar, S., Tiwari, S., Singh, B. P., Bisht, D. S., \& Tiwari, S. (2014). Characterisation of Atmospheric Aerosol by SEM-EDX and Ion- Chromatography Techniques for Eastern Indo-Gangetic Plain Location, Varanasi, India. International Journal of Advances in Earth Sciences, ISSN 2278-0092

Srivastava, A., Jain, V.K., Srivastava, A.: SEM-EDX analysis of various sizes aerosols in Delhi India. Environ. Monit. Assess. 150, 405-416 (2009). https://doi.org/10.1007/s10661-008-0239-0

Suárez-Peña, B., Negral, L., Castrillón, L., Megido, L., Marañón, E., Fernández-Nava, Y.: Imaging techniques and scanning electron microscopy as tools for characterizing a Si-based material used in air monitoring applications. Materials. 9, (2016). https://doi.org/10.3390/ma9020109

Tsuji, K., Nakano, K., Hayashi, H., Hayashi, K., Ro, C.U.: X-ray spectrometry. Anal. Chem. 80, 4421-4454 (2008). https://doi.org/10.1021/ac800678s

Vaishya, A., Nair Suresh Babu, S., Jayachandran, V., Gogoi, M.M., Bharathan Lakshmi, N., Krishna Moorthy, K., Krishnakumari Satheesh, S.: Large contrast in the vertical distribution of aerosol optical properties and radiative effects across the indo-Gangetic plain during the SWAAMI-RAWEX campaign. Atmos. Chem. Phys. 18, 17669-17685 (2018). https://doi.org/10.5194/acp-18-17669-2018

Virkkula, A., Teinilä, K., Hillamo, R., Kerminen, V.M., Saarikoski, S., Aurela, M., Viidanoja, J., Paatero, J., Koponen, I.K., Kulmala, M.: Chemical composition of boundary layer aerosol over the Atlantic Ocean and at an Antarctic site. Atmos. Chem. Phys. 6, 3407-3421 (2006). https://doi.org/10.5194/acp-6-3407-2006

Wang, B., Laskin, A.: Reactions between water-soluble organic acids and nitrates in atmospheric aerosols: recycling of nitric acid and formation of organic salts. J. Geophys. Res. 119, 3335-3351 (2014). https://doi. org/10.1002/2013JD021169

Wang, Y.F., Li, C.T., Mi, H.H., Luo, J.H., Tsai, P.J.: Emissions of fuel metals content from a diesel vehicle engine. Atmos. Environ. 37, 4637-4643 (2003). https://doi.org/10.1016/j.atmosenv.2003.07.007

Warner, J.X., Dickerson, R.R., Wei, Z., Strow, L.L., Wang, Y., Liang, Q.: Increased atmospheric ammonia over the world's major agricultural areas detected from space. Geophys. Res. Lett. 44, 2875-2884 (2017). https://doi.org/10.1002/2016GL072305

Willis, R. D., Blanchard, F. T. \& Conner, T. L. (2002). Guidelines for the application of SEM/EDX analytical techniques to particulate matter samples, U.S. Environmental Protection Agency, EPA \# 600/R-02/070

Yao, X., Chan, C. K., Fang, M., Cadle, S., Chan, T., Mulawa, P., He, K., \& Ye, B. (2002). The water-soluble ionic composition of PM2.5 in Shanghai and Beijing, China. Atmospheric Environment. 10.1016/S13522310(02)00342-4

Publisher's note Springer Nature remains neutral with regard to jurisdictional claims in published maps and institutional affiliations. 


\section{Affiliations}

Mukunda M. Gogoi ${ }^{1} \cdot$ Roseline C. Thakur $^{2} \cdot$ Sahina Gazi ${ }^{3} \cdot$ Vijayakumar S. Nair $^{1} \cdot$ Rahul Mohan $^{3} \cdot$ S. Suresh Babu ${ }^{1}$

$\triangle$ Mukunda M. Gogoi

dr_mukunda@vssc.gov.in

1 Space Physics Laboratory, Vikram Sarabhai Space Centre, Trivandrum 695 022, India

2 Institute for Atmospheric and Earth System Research (INAR) / Physics, Faculty of Science, University of Helsinki, FIN-00100 Helsinki, Finland

3 National Centre for Polar and Ocean Research, Ministry of Earth Sciences, Vasco da Gama, Goa 403 804, India 